\title{
DOES HERDING AFFECT VOLATILITY? IMPLICATIONS FOR THE SPANISH STOCK MARKET
}

\author{
Blasco, Natividad \\ Corredor, Pilar ${ }^{\#}$ \\ Ferreruela, Sandra* \\ *Department of Accounting and Finance (University of Zaragoza) \\ \#Department of Business Administration (Public University of Navarre)
}

\begin{abstract}
:
According to rational expectation models, uninformed or liquidity trading make market price volatility rise. This paper sets out to analyze the impact of herding, which may be interpreted as one of the components of uninformed trading, on the volatility of the Spanish stock market. Herding is examined at the intraday level, considered the most reliable sampling frequency for detecting this type of investor behavior, and measured using the Patterson and Sharma (2006) herding intensity measure. Different volatility measures (historical, realized and implied) are employed. The results confirm that herding has a direct linear impact on volatility for all of the volatility measures considered although the corresponding intensity is not always the same. In fact, herding variables seem to be useful in volatility forecasting and therefore in decision making when volatility is considered a key factor.
\end{abstract}

Key words: Herding, Capitals market, behavioral finance, volatility

JEL codes: G14, G10

\section{ACKNOWLEDGEMENTS}

The authors are grateful to the anonymous referees and editors for their helpful comments and suggestions with respect to the first version of our paper. 
* The authors wish to acknowledge the financial support of the Spanish Ministry of Education and Science (SEJ2006-14809-C03-03/ECON), the Spanish Ministry of Science and Innovation (ECO2009-12819-C03-02), ERDF funds, the Caja de Ahorros de la Inmaculada (Europe XXI Programme) and the Government of Aragon.

\# The author is grateful for the financial support of the Spanish Ministry of Education and Science (SEJ2006-14809-C03-01), the Spanish Ministry of Science and Innovation (ECO2009-12819-C03-01), ERDF funds and the Government of Navarra. 


\section{Introduction}

Price volatility in capital markets is a key topic in finance: the basis of pricing models, investment and risk management strategies and market efficiency models is accurate volatility measurement. In an ideal world where the market is efficient, prices instantaneously adjust to new information. Therefore volatility is only caused by the continuous adjustment of stock prices to new information. There is nevertheless abundant evidence, both in the literature and among practitioners, of price adjustments that are due not to the arrival of new information but to market conditions or collective phenomena such as herding (Thaler [1991], Shefrin [2000]). Thus, we cannot talk of efficient pricing or indeed of an efficient market, at least in the strict traditional sense. The market may operate under a limited rationality paradigm in which historical information is open to investors' subjective interpretation.

Herding is said to be present in a market when investors opt to imitate the trading practices of those they consider to be better informed, rather than acting upon their own beliefs and private information. Herd trading, therefore, despite sometimes being rational, cannot be considered an informed trading strategy, since herders imitate other investors even when in possession of their own information. Some of the main ideas advanced to explain this behavior are based on how the information is transmitted (Banerjee [1992], Bikhchandani, Hirshleifer and Welch [1992], Hirshleifer, Subrahmanyam and Titman [1994], Gompers and Metrick [2001] or Puckett and Yan [2007]), reputation costs (within agency theory and only in developed markets, Scharfstein and Stein [1990], Trueman [1994]) and finally, agent compensation based on performance relative to a benchmark (Roll [1992], Brennan [1993], Rajan [1994] or Maug and Naik [1996]). Some authors have recently suggested new explanations such as the degree of institutional ownership, the quality of the information released, dispersion of investor beliefs or the presence of uninformed investors, among others (see Patterson and Sharma [2006] henceforth PS, Demirer and Kutan [2006], Henker, Henker and Mitsios [2006] and Puckett and Yan [2007]).

Generally speaking, most of the studies carried out to test for herding in capital markets have proved inconclusive. Hence, in recent years various measures have been proposed with a view to overcoming the limitations of past research (Lakonishok, Schleifer and Vishny [1992], Christie and Huang [1995], Wermers [1999], Chang, 
Cheng and Khorana [2000], Hwang and Salmon [2004], PS[2006]). Radalj and McAleer (1993) note that the main reason for the lack of empirical evidence of herding may lie in the choice of data frequency, in the sense that too infrequent data sampling would lead to intra-interval herding being missed (at monthly, weekly, daily or even intradaily intervals). For the purposes of our investigation we used the PS(2006) measure, which we consider the most suitable, since it overcomes this problem by being based on intraday transactions data. We are aware of the risks attached to opting for one measure or another since it is difficult to isolate herding from other variables. We nevertheless feel that this should not raise any obstacles if we are to continue advancing research into investor behaviour.

The link between investor behaviour and market volatility was first noted by Friedman (1953) who found that irrational investors destabilized prices by buying when prices were high and selling when they were low, while rational investors tended to move prices towards their fundamentals, by buying low and selling high. Following Friedman and the theory of Noisy Rational Expectations, Hellwig (1980) and Wang (1993) claimed that volatility is driven by uninformed or liquidity trading, given that price adjustments arising from uninformed trading tend to revert. The latter author observes that information asymmetry may drive volatility and that uninformed investors largely tend to follow the market trend, buying when prices rise and selling when they fall; a behavior that we might consider tantamount to herding. Wang (1993) reports that, although it is uninformed trading, this behavior may be rational in less informed investors if it takes place in a context of asymmetrical information. Froot, Scharfstein and Stein (1992) also concluded that investors tend to imitate one another, and that this drives volatility. More recently this relationship has been documented by Avramov, Chordia and Goyal (2006), who claim that both herding and contrarian trading have a strong impact on daily volatility ${ }^{1}$.

Following the authors who have observed the behavior of market agents to have a certain influence on existing volatility, we set out to assess the effect of different levels of herding intensity on the degree of market volatility. As a first stage in the procedure, we take some series of the various volatility measures used in the literature, such as absolute return residuals, realized volatility (Andersen et al [2001]), historical volatility (Parkinson [1980] and Garman and Klass [1980]) and implied volatility from

\footnotetext{
${ }^{1}$ For further information on the relationship between uninformed investors and volatility, see also Black (1976), De Long et al (1990) and Campbell and Kyle (1993).
} 
the options market. Given that the literature has documented volume traded effects (Lamoureux and Lastrapes [1990]) and day-of-the-week effects (French, [1980], Agrawal and Tandon [1994]) on volatility, the volatility series have been purged of both these effects. In this way we are able to study the herding effect on our volatility series without running the risk of confusing other previously known effects with the one we wish to analyze. In a second stage we analyze both the linear and non-linear relationships between the volatility variables and herding. Finally we test whether our results are useful for forecasting purposes comparing traditional volatility models with others including herding measures.

The study focuses on the Spanish stock exchange's benchmark index, the Ibex35, which tracks the 35 most traded shares, and which we consider to be representative of the market as a whole. The Spanish market is a suitable framework in which to centre this analysis because it is one with documented evidence of herding (see Blasco and Ferreruela [2007, 2008], Lillo et al [2007] and Blasco, Corredor and Ferreruela [2010]). In order to provide valid conclusions, we carry out a complementary analysis using both the largest and smallest capitalization stocks belonging to the Ibex-35 (large cap index and small cap index), for determining whether our results are due to one type of stock or another.

Fundamentally this study contributes to providing an explanation for that portion of volatility that is not due to changes in fundamentals or other known effects. It also adds to the literature on the herding behavior of investors and advances the understanding of the phenomenon and the search for the possible implications of different levels of herding on the market, since empirical relationships are established between herding intensity and market volatility. The results could prove highly relevant in achieving a better understanding of market functioning and serve both academics and practitioners, given that an understanding of which variables affect volatility and the nature of their influence could contribute to much more accurate forecasting and, furthermore, to the definition of new risk measures or new hedging strategies. In fact, some authors (e.g. Crépey 2004) explain how the different volatility regimes exhibited in certain markets may require especially useful alternative volatility measures, and how market complexity and incompleteness of the volatility measures are drawbacks that call for a recalibration of the models used for risk management. Other authors (Demetrescu, 2007) find that volatility clusters can appear as a consequence of the 
volatility forecasting activity itself. Traders use different models to evaluate stock volatility. An increase in recently observed volatility leads to higher estimates of current volatility and thus higher perceived market risk. The higher the risk perceived, the higher the price correction. Hence, present and past volatility estimates are linked in a feed-back loop that might be worthy of analysis.

At this point we should ask ourselves whether that part of volatility due to herding, if present, could be hedged or diversified or, in other words, whether implied volatility in derivatives includes the herding component or only future information or uncertainty. All these aspects are key factors in investment decision-making and portfolio or risk management.

Other important features of the study are the use of a daily herding measure computed from intraday information, since this data is thought to be the most appropriate when trying to detect herding behavior, and the use of several volatility indicators in the analysis of the effects on volatility, both of which will increase the robustness of our results. Lastly, the time period analyzed is long enough to dilute any biases due to temporary market fluctuations.

The remainder of the paper is structured as follows: section two presents the database used in the analysis with some descriptive statistics of the Spanish stock market. Section three describes the methodology and presents the main findings. Section four summarizes the main conclusions derived from the study.

\section{2.- Database}

The sample period runs from January $1^{\text {st }} 1997$ to December $31^{\text {st }} 2003$. The data were supplied by the Spanish Sociedad de Bolsas SA. The intraday data used to calculate the herding variable and to calculate the forecasting models include the date, exact time in hours, minutes and seconds, stock code, price and volume traded in number of titles of all trades executed during the period January 1997 to June 2003, leaving the period July 2003 to December 2003 for forecasting assessment.

The Ibex-35 index tracks the movements of the 35 most liquid and most traded stocks in the Spanish continuous market. For the purposes of our analysis we used the composition of the Ibex-35, the volume in Euros traded and the number of trades for each of the listed stocks, together with the daily opening, closing, maximum and 
minimum price series for the period. Further, we used Ibex-35 15 minute price data also supplied by the Spanish Sociedad de Bolsas SA. We exclude from the analysis all trades executed outside regular trading hours (10 a.m. to 5 p.m. for the whole of 1997, later extended by stages from 9 a.m. to 5:30 p.m. by 2003). Hence, the data used in this analysis cover all trades executed on Ibex-35 stocks at any time during regular stock exchange trading hours.

The implied volatilities of the options on the Ibex-35 were drawn from a database containing historical close of trade data for the derivatives market, provided by MEFF (the official Spanish futures and options market), including the date of trade, the underlying asset of the contract (in our case the Ibex-35), contract expiry date, exercise price and implied volatility at the close of trading ${ }^{2}$.

\section{3.- Methodology and results}

\section{1- Herding measures}

\subsection{1- Herding intensity statistic}

To measure herding intensity in the market, this study uses the measure proposed by PS(2006), which is based on the information cascade models of Bikhchandani, Hirshleifer and Welch (1992), where herding intensity is measured in both buyer- and seller-initiated trading sequences. This measure has a major advantage over others in that it is constructed from intraday data, that is, a daily indicator is obtained but from intraday data, since we consider this to be the ideal frequency of data to test for the presence of this kind of investor behaviour. This has the further advantage for our purposes that it does not assume herding to be revealed only under extreme market conditions as occurs in other methodological proposals, and that it considers the market as a whole rather than a few institutional investors as has been usual practice in the empirical literature.

In the model developed by Bikhchandani, Hirshleifer and Welch (1992) information cascades occur when investors base their decisions on the actions they observe in others, which they allow to override their own information. The probability

\footnotetext{
${ }^{2}$ We use in this paper those implied volatilities offered by the MEFF. However, we previously computed the implied volatilities for the period 1997-1998 by numerical simulation inverting the Black-Scholes model. We carried out the analysis with these data and the results do not change significantly when compared with those obtained using the implied volatilities available from the MEFF.
} 
of an information cascade is very high even if only a few early traders have made their investment decision.

Following these theories, PS(2006) asserted that empirically an information cascade will be observed when buyer-initiated or seller-initiated runs last longer than would be expected if each individual investor were to base his trading decisions exclusively on private signals. These authors propose a statistic that measures herding intensity in terms of the number of runs. If traders engage in systematic herding, the statistic should take significantly negative values, since the actual number of runs will be lower than expected.

$$
x(s, j, t)=\frac{\left(r_{s}+1 / 2\right)-n p_{s}\left(1-p_{s}\right)}{\sqrt{n}}
$$

where $r_{s}$ is the actual number of type $s$ runs (up runs, down runs or zero runs), $n$ is the total number of trades executed on asset $j$ on day $t, 1 / 2$ is a discontinuity adjustment parameter and $p_{s}$ is the probability of finding a type of run $s$ (a priori $\left.p_{i}=1 / 3\right)^{3}$. Under asymptotic conditions, the statistic $x(s, j, t)$ has a normal distribution with zero mean and variance

$$
\sigma^{2}(s, j, t)=p_{s}\left(1-p_{s}\right)-3 p_{s}^{2}\left(1-p_{s}\right)^{2}
$$

Finally, PS(2006) define their herding intensity statistic as:

$$
H(s, j, t)=\frac{x(s, j, t)}{\sqrt{\sigma^{2}(s, j, t)}} \stackrel{a . d}{\longrightarrow} N(0,1)
$$

where $s$ takes one of three different values according to whether the trade is buyer-initiated, seller-initiated, or zero tick, such that we have three series of $\mathrm{H}$ statistics. Ha denotes the series of statistic values for up (buyer-initiated) runs, $\mathrm{Hb}$ denotes those for down (seller-initiated) runs, and Hc those for runs with no price

\footnotetext{
${ }^{3}$ Under the null hypothesis that stock prices follow a random walk reacting quickly and completely to the arrival of new information and if there is no discernible pattern in the information arrival process, then the probability assignable to each type of price sequence should be the same. However, given that stock markets may reflect other tendencies or phenomena than herd behaviour that may influence such probability, as shown by the results in Blasco, Corredor and Ferreruela (2009b), we have selected a sample of stocks that do not present any evidence of herd effects and we have calculated the probability of upwards/downwards and zero-tick price sequences. In the Spanish market, upwards and downwards sequences occur with a $30 \%$ probability for each. Zero-tick sequences occur over our time horizon with a $40 \%$ probability. In this paper we use the case of $\mathrm{p}_{\mathrm{i}}=1 / 3$, given that the significance and the conclusions do not change significantly because of the high herding intensity (the use of the alternative probabilities only implies a $10 \%$ reduction in the absolute value of the $\mathrm{H}$ statistics).
} 
change, also known as zero runs. To categorize trades as buys or sells PS use the tick test $^{4}$. In our analysis we follow the same method. ${ }^{5}$

To construct the herding intensity measures required for our study, we begin by sorting the trades for each day (having excluded all those executed outside regular trading hours) by stock code and measuring the number of (up, down or zero) runs that took place that day, and then calculating the PS(2006) statistic. Thus, Ha, Hb and Hc statistics are calculated using each individual stock in the index and then summed up across all the stocks in the corresponding index ${ }^{6}$.

For long samples, $\mathrm{H}(\mathrm{i}, \mathrm{j}, \mathrm{t})$ is normally distributed according to $\mathrm{N}(0,1)$. Nevertheless, following the indications in PS(2006), when the discretization of prices may modify the critical values, a bootstrap procedure can be used to assess the significance of the estimations. The bootstrap procedure designed in this paper starts from the choice of an initial sample of Spanish stocks that do not show any evidence of herd behaviour according to the results in Blasco, Corredor and Ferreruela (2009a) and, therefore, properly represent the null hypothesis of absence of herding effect. By resampling 1000 bootstrap replicas, each one including about 1000 transactions, we calculate the number of sequences of each type and compare with the theoretical number $n . p_{i \cdot}\left(1-p_{i}\right)$ and then compute the bootstrap distribution of $\mathrm{H}$.

\subsection{2-Some characterization of the herding intensity statistic.}

Table I shows the descriptives for the herding intensity measures, where it can be seen that, on average, herding intensity is significantly negative (when assessed with either the normal distribution or the bootstrap procedure) across all types of run (up runs, down runs, and zero runs), but that a notable difference can be observed between the first two (-8.81 and -8.72 respectively when the overall Ibex35 is analyzed) and the last (-4.03), with much higher herding intensity levels emerging when there are price

\footnotetext{
${ }^{4} \mathrm{~A}$ trade is classed as a buy if the price is higher (an up-tick) than the most recent previous trade, and as a sell if the price is lower (a down-tick) than the most recent previous trade. If the price is the same as the most recent previous trade, the trade is classed as a zero-tick.

${ }^{5}$ There are different means to identify a transaction as a buy or a sell. Finucane (2000) demonstrates how this method yields similar results to others. This, together with the unavailability of a database that included the bid-ask spread, led us to opt for the tick test to categorise trades.

${ }^{6}$ In order to see whether there is any link between the herding statistic and the return dispersion measures suggested in the literature, we calculate the correlation coefficients between variations in the $\mathrm{H}$ values and the corresponding variations in the cross-sectional standard deviation proposed by Christie and Huang, (1995). We find a positive correlation, as expected, of $12 \%$. We also observe that upwards or downwards variations of these measures agree in around $60 \%$ of cases.
} 
changes (up runs and down runs) than where there is no price change (zero runs). In other words, significant herding took place on Ibex-35 stocks ${ }^{7}$ throughout practically the whole of the sample period.

Although all the stocks included in the Ibex35 exhibit a significant $\mathrm{H}$ statistic, we want to determine whether those stocks with larger capitalization may exhibit a more intense mimetic behaviour or not. The literature on the relationship between size and herding focuses on two alternative arguments. On the one hand there are the arguments for a higher herding level in small firms based primarily on account of firm size as a risk factor in asset returns. The difficulty for assessing small firms and the view of scarce information about them (PS [2006] and Wermer [1999]) support this idea. On the other hand, the arguments in favour of higher level of herding in large firms focus on the greater flow of information increasing the likelihood of imitative behavior (Sias,2004), either because uninformed investors, intentionally or not, tend to invest in large versus small stocks by familiarity (Palomino,1996), or because institutional investors mainly use large firms for restructuring portfolios or portfolio benchmarking. Along the same lines, Lin, Tsai and Sun (2009) find that investor herding is more pronounced in those stocks with good information quality, as is the case with larger firms. These authors suggest that herding is caused by the search cost effect, that is to say, individual investors may prefer to trade the stocks which require lower search costs, and those stocks are mainly the ones with larger market capitalization. Stocks with higher market caps and turnovers are the easiest to sell in a very short period of time so sellers with liquidity constraints would naturally flock to markets for these stocks.

In order to analyse the possible differences, we estimate the herding measure for the stocks belonging to the selected extreme quintiles among the stocks included in the Ibex-35. The results are also included in Table I. The first quintile (small caps) and the fifth quintile (large caps) show significant differences. Large capitalization firms are more prone to higher herding effects $^{8}$ than small capitalization firms, all being

\footnotetext{
7 A preliminary analysis of the complete Spanish stock market produced evidence that, although the financial assets not included in the Ibex35 showed negative $\mathrm{H}$ values, no significant values of the herding measure could be found. That is why only those assets belonging to the index are considered in this paper. 8 The t-statistic for the null hypothesis of no mean difference between small and large capitalization stocks is 90.28 for $\mathrm{Ha}, 89.49$ for $\mathrm{Hb}$ and 69.12 for Hc. This lends weight to the idea that firm size may influence the herd behaviour of agents.
} 
significant. This implies that firm size (identified by capitalization) may be considered a characteristic attractor of herd behaviour.

In order to provide some complementary results that may be useful for locating the mimetic behaviour of investors, we apply the SUR methodology (Seemingly Unrelated Regression) for determining the importance of two other key factors: the up/down situation of the market and the trading volume. For identifying the first explanatory variable, we include a dummy variable that takes value 1 during down market periods (from $1^{\text {st }}$ October 1997 to $28^{\text {th }}$ October 1997 , from $17^{\text {th }}$ July 1998 to $1^{\text {st }}$ October 1998 and from $6^{\text {th }}$ March 2000 to $9^{\text {th }}$ October 2002) and 0 otherwise. The structure of the regressions is as follows:

$$
\begin{aligned}
& H_{a t}=\alpha_{a 0}+\delta_{a j} \sum_{j=1}^{k} H_{a t-j}+\alpha_{a 1} D_{d t}+u_{a t} \\
& H_{b t}=\alpha_{b 0}+\delta_{b j} \sum_{j=1}^{k} H_{b t-j}+\alpha_{b 1} D_{d t}+u_{b t} \\
& H_{c t}=\alpha_{c 0}+\delta_{c j} \sum_{j=1}^{k} H_{c t-j}+\alpha_{c 1} D_{d t}+u_{c t}
\end{aligned}
$$

where $\mathrm{H}_{\mathrm{at}}$ indicates up (buyer-initiated) runs, $\mathrm{H}_{\mathrm{bt}}$ denotes those for down (sellerinitiated) runs, $H_{c t}$ indicates zero runs and $D_{d}$ is the dummy variable. Some lags of the herding measure have been included to avoid autocorrelation problems in the estimation process. The results for the dummy variable are shown in Table II. Herding intensity significantly increases in crisis or down market periods. It is worth noting that in crisis periods, uncertainty and loss aversion may induce investors to mimic the decisions of others that are thought to be better informed or more able to process the information arriving in the market.

Applying the same methodology, we have also analyzed trading volume as an explanatory factor of herding intensity. In this case, trading volume $\left(\mathrm{V}_{\mathrm{t}}\right)$ is a continuous variable. The results are also presented in Table II. We find significant estimates suggesting that the larger the trading volume, the more intense the herding effect in the market.

Combining all these elements, we suggest that firms with larger capitalization and high trading volume in down market situations set the ideal conditions for inducing intense mimetic behaviour in investors. Perhaps uninformed investors who choose to invest in stocks that seem familiar to them (because they generate a large amount of publicly available information and are very likely to be properly assessed by analysts), 
rationally decide to imitate the decisions of others that are thought to be better informed than them with the aim of reducing their risk exposure. The better the characterization of the herding intensity, the better the design of forecasting strategies and decision making. ${ }^{9}$

\subsection{3-Further discussion.}

Some recent empirical literature has demonstrated long-memory in the signs of orders to buy or sell in stock markets (see, among others, Bouchaud et al. 2004 and Lillo and Farmer, 2004). Bouchad, Farmer and Lillo (2008) suggest that this long memory may be caused by a property of the order flow of each investor, independent of the behavior of other investors, by the common practice of order splitting or, alternatively, it may be due to herding behavior (see also Cont and Bouchaud, 2000). Under this view, high frequency strategies play an important role. Such strategies are not only processing fundamental information, but rather acting as technical trading strategies based on the information contained in the time series of prices and other information that is completely internal to the market.

The results in Blasco and Ferreruela (2007) indicate that order splitting basically occurs along zero-tick sequences, given the brokers' aim of avoiding unfavorable price changes. Additional to the usefulness of providing separate results for our herding measures $\mathrm{H}_{\mathrm{a}}, \mathrm{H}_{\mathrm{b}}$ and $\mathrm{H}_{\mathrm{c}}$, in order to avoid biased conclusions, these authors find that only a small percentage of the transactions implying a price change, about $2 \%$, could be attributed to splitting practices $^{10}$.

Lillo et al. (2008) also detect herding in the buying and selling activity of brokerage firms in the Spanish Stock Exchange and show that firms trading in this market are characterized by detectable trending or reversing resulting strategies associated to a characteristic pattern of herd behavior both at daily and at intradaily time horizons. Similarly, Blasco et al. (2009a) explore the usefulness of an investment strategy designed for those stocks attracting imitative behaviour in the Spanish market.

\footnotetext{
${ }^{9}$ Blasco, Corredor and Ferreruela (2009a) offer further details for the characterization of the herding effect in all stocks in the Spanish market.

10 The authors additionally carry out an additional test for detecting "leader brokers" in the Spanish market with the aim of empirically corroborating the arguments in favour of the presence of herd behaviour. They find that a small number of brokers who very often initiate the transaction sequences either as buyers or sellers, being the rest of the brokers considered as followers.
} 
All these comments suggest that microstructural effects may influence the value of the volatility. The persistence in volatility, first documented by Engle (1982), may be influenced by microstructure components such as herding on short time scales rather than by the arrival of new information. La Spada et al. (2008) show that a subtle longrange non-contemporaneous correlation between signs and sizes of price changes (nonzero returns) may cause over-predictions of volatility for highly capitalized stocks. Bouchaud et al. (2004) find that the sign of the trades shows surprisingly long range correlations that can be subtly "corrected" by a mean reversion process in prices induced by liquidity providers. We try to add to this line of research by studying the implications for volatility of a herding measure that identifies the sign of transaction with the sign of return. Once such mimetic behavior has been detected in a market we are interested in addressing how this strategic motivation (rather than some of its statistical reflections) may influence volatility.

\section{2- Volatility measures}

\subsection{1- Absolute return residuals}

The first of the volatility measures considered in this paper is the absolute return residual, which is obtained from the following regression:

$$
R_{i t}=\sum_{k=1}^{5} \alpha_{i k} D_{k t}+\sum_{j=1}^{12} \omega_{i j} R_{i t-j}+\varepsilon_{i t}
$$

where $R_{i t}$ is the index return $i$ on day $t$, which can take one of four values: AA if it is the return calculated from opening on day $t$ to opening on day $t+1$, AC if what is being measured is the return from opening to closing on day $t, \mathrm{CC}$ if it is the return from closing on day $t-1$ to closing on day $t$, and finally, CA if we are measuring the return from closing on day $t$ to opening on day $t+1$. Following French (1980) and Keim and Stambaugh (1984) we include the variable $D_{k t}$ to represent the day-of-the-week dummies in order to capture differences in mean returns that are due exclusively to variations in market performance on different days of the week. Finally, to remove autocorrelation from the return series, we include the variable $R_{i t-j}$ as the lagged return variable. $\left|\varepsilon_{i t}\right|$ provides a volatility measure for each of the series used.

The first four columns of Table III give the descriptive statistics for the four resulting volatility measures. On average there are no major differences, the highest 
value being that of $\left|\varepsilon_{A A}\right|$ at 0.0129 , and the lowest that of $\left|\varepsilon_{C A}\right|$, at 0.0061 . This is consistent with market functioning since $\left|\varepsilon_{C A}\right|$ is the only one of these measures that captures exclusively volatility over non-trading hours and, generally speaking, news likely to trigger volatility is more likely to emerge during trading hours than during nontrading time.

\subsection{2- Realized volatility}

The second of the volatility measures considered is realized volatility. Merton (1980) already showed that accurate volatility estimators can be obtained using fixedinterval data, as long as the intervals tend towards zero, given that prices follow a geometric Brownian motion and estimation error in the return variance is proportional to the length of the interval, such that it decreases with shorter intervals. Andersen et al. (2001) show that by summing the squares of intraday returns calculated from high frequency data it is possible to obtain an accurate volatility estimator and find that, when the frequency of the data tends towards infinity, it is possible to obtain a volatility estimator that is error free and equal to real volatility. The variance of the discrete returns measured at numerous intervals is known in the literature as the integrated variance $\overline{\sigma_{t}^{2}}$ which is a natural measure of real volatility ${ }^{11}$ where $\overline{\sigma_{t}^{2}}=\int_{0}^{1} \sigma_{t-\tau}^{2} d \tau$.

The integrated volatility estimator, known as realized volatility, is obtained by summing intraday squared returns (m) according to the following expression:

$$
\sigma_{R}=\bar{\sigma}_{t}^{2}(m)=\sum_{k=1}^{m} r^{2}{ }_{t+k / m}
$$

Where $r_{t+k / m}$ is the return for each of the short intervals into which the trading session is divided ${ }^{12}$.

Following this methodology, this paper uses two measures of realized volatility: one is realized volatility, measured from opening to closing of trade on day $t$, which we

\footnotetext{
${ }^{11}$ For further information on realized volatility, see French, Schwert and Stambaugh (1987), Schwert (1989) and Ferland and Lalancette (2006).

${ }^{12}$ Bandi and Russell (2008) obtain optimal intervals for the calculation of realized volatility and show errors for 5-minute intervals to be approximately equal to those of the optimal interval, where the 5minute interval is the one used to calculate realized volatility in the majority of empirical studies. We were forced by the lack of superior data to use 15 -minute intervals to calculate this measure of volatility. Nevertheless, Andersen et al. (2000) showed in an experiment that volatilities start to stabilize at 30 minute intervals. Our results can therefore be considered free of significant error, thanks to the data frequency used.
} 
will denote by $\sigma_{R-A C}$; the other is realized volatility including overnight data, that is, events occurring from opening of trading on day $t$ to opening of trading on day $t+1$, which we denote by $\sigma_{R-A A}$.

Columns five and six in Table III show the descriptive statistics for the daily series of these two realized volatility measures. On average, the results are similar to those obtained in the previous measures, with slightly higher values of realized volatility being observed when overnight data are taken into account. $\left(0.0120\right.$ for $\sigma_{R-A C}$ and 0.0142 for $\left.\sigma_{R-A A}\right)$. While the minimum values are similar for both measures, the opening to opening realized volatility measure shows the higher maximum value.

\subsection{3- Historic volatility: Parkinson and Garman-Klass}

Thirdly we use the historical volatility measures proposed by Parkinson (1980) and Garman and Klass (1980).

Parkinson's measure takes the maximum and minimum daily prices of an asset (in our case we take the Ibex-35 as one more asset). The collection of these prices is more effort-intensive than that of the opening and closing prices used in the construction of other measures of historic volatility, since it requires continuous observation of the market, but, since extreme price data is more informative than opening and closing price data, the extra effort may provide added value to the results. The reason for this is that volatility reverts to the mean once it reaches extreme values, and this estimator therefore facilitates the tracking of extreme volatilities and enables forecasting.

We calculate Parkinson's estimator according to the following expression:

$$
\sigma_{P}=\frac{1}{2 \sqrt{\ln 2}} \sqrt{\frac{1}{n} \sum_{t=1}^{n} P_{t}^{2}}
$$

where $P_{t}=\ln \frac{H_{t}}{L_{t}}$, and $H_{t}$ and $L_{t}$ are, respectively, the maximum and minimum Ibex-35 prices on day $t$ and $\mathrm{n}$ is the number of historical daily prices used in the volatility estimate. The initial choice in this paper is $n=1$, given our aim of finding significant relations between daily herding and daily volatility ${ }^{13}$.

\footnotetext{
13 Nevertheless, we made some previous tests using values of $\mathrm{n}=5,50,250$ and running a rolling procedure. The results were still significant although the coefficients rapidly decrease when $n$ increases.
} 
Garman and Klass suggest a slightly different approach to estimate historical volatility, in which opening and closing prices as well as extreme prices are included. We calculate historical volatilities according to the following expression:

$$
\sigma_{G K}=\sqrt{\frac{1}{n} \sum_{t=1}^{n}\left[\frac{1}{2} P_{t}^{2}-(2 \ln 2-1) Q_{t}^{2}\right]}
$$

where $Q_{t}=\ln \frac{C_{t}}{O_{t}}$, and $C_{t}$ and $O_{t}$ are, respectively, the Ibex-35 opening and closing prices on day $t$ and $\mathrm{n}$ is the number of historical prices used in the volatility estimate. We take $n=1$ as before.

The next two columns of Table III show the descriptive statistics for the time series volatilities calculated by these measures. No major differences emerge between the two. On average (0.012 for Parkinson's estimator and 0.0117 for the Garman-Klass estimator) the two are very similar to the measures presented so far. The level of leptokurtosis in the distribution is lower than in most of the other measures presented. The coefficients (11.30 for Parkinson's estimator and 10.10 for the Garman-Klass estimator) are similar to that of $\left|\varepsilon_{\mathrm{AC}}\right|$ the only lower one being that of $\left|\varepsilon_{\mathrm{CC}}\right|$ (3.89).

\subsection{4- Implied volatility}

All the volatility measures presented so far use spot market data. Nevertheless, several studies of the S\&P100 index coincide in stating that implied volatility in at-themoney (henceforth ATM) options is a more efficient volatility estimator than those based exclusively on historical data. Fleming (1998) and Christensen and Prabhala (1998) among others, and more recently, for the Spanish stock market, Corredor and Santamaría $(2001,2004)$ show that implied volatility is a reliable predictor of future volatility versus other volatility measures. There are also numerous studies showing that the implied volatility indexes currently being constructed in several countries across the world possess significant power to predict future volatility in the stock market (Fleming, Ostdiek and Whaley [1995], Simon [2003], Giot [2005]).

Some recent papers have claimed that implied volatility also reflects investor sentiment (Baker and Wurgler [2006]). This led us to ask ourselves whether this measure may be sensitive to the presence of herding behavior in the stock market. We believe that the inclusion of this variable as an additional volatility measure in this 
paper will help to obtain a much more detailed as well as broader picture of the impact of herding on volatility.

Implied volatility measures resulting from the inversion of Black and Scholes (1973) (henceforth BS) pricing model are used. The main reason is convenience, given that these measures are available in the market (which can also make them affect investor expectations). In a theoretical framework, Fleming (1998) argued that in short term and ATM options, the BS model gives estimations virtually identical to the ones given by other stochastic volatility models. Following the above literature, we now focus on the implied volatility in short-term (ST) ATM call options on the Ibex-35 (with 30 days or less to maturity).

The last column of Table III shows observable differences between descriptive statistics for implied volatility and the historical volatility measures. Implied volatility presents a slightly higher average than the previous measures (0.0165) and a closer to normal distribution, with a short-run asymmetry coefficient of 0.0493 and a kurtosis level of 1.7191 .

Table IV shows the existing correlation between the various volatility measures used in this paper. The correlation is low in overall terms, suggesting that it makes sense to use different measures because each one may supply additional information to the analysis. Not surprisingly, in view of the way in which they are constructed, the most highly inter-correlated are the Parkinson and Garman Klass measures, with a correlation coefficient of 0.8962 . They are followed by $\sigma_{R-A C}$, with a correlation coefficient of 0.8794 with $\sigma_{R-A A}$ (which is also foreseeable from the method used in their calculation), 0.8167 with $\sigma_{P}$ and 0.8638 with $\sigma_{G K}$.

\section{3- Volatility and herding}

\subsection{1- Obtaining series free of day-of-the-week and volume effects.}

Having obtained the volatility measures described above, the second stage of the study is to purge them of the volume and day-of-the-week effects documented in the literature. We did this by running a series of regressions in which each of the abovedescribed volatility measures was made to depend on the Monday effect and on a proxy for the daily trading volume and then corrected for autocorrelation. Thus, and subsequently taking the residuals of these regressions, we obtained series in which the 
only effects would be due to factors other than volume or the day-of-the-week effects, which, if present, would be captured by the coefficients of the variables considered.

There is a vast amount of evidence to show that volume traded and return volatility are positively correlated (Karpoff [1987], Gallant, Rossi and Tauchen [1992], Jones, Kaul and Lipson [1994]). The two paradigms that attempt to explain this relationship are the mixture of distributions (Epps and Epps, [1997]) and the microstructure paradigm (O`Hara, [1995]). From a number of empirical studies that use different measures of volume to test these paradigms, we have taken Jones, Kaul and Lipson (1994) and Chan and Fong (2000, 2006). Following these papers, we use three different measures of volume: the traditional measure of volume traded in Euros, the number of trades, and the average trade size in Euros.

Table $\mathrm{V}$ gives the correlations between the various volume measures considered; volume traded in Euros $(V)$, number of trades $(N T)$ and average trade size (ATS). Most notable in the table are the high correlation between $V$ and $N T(0.8149)$ and the negative correlation between $N T$ and ATS (-0.2256). Given the existing controversy in the literature over which of these factors actually have an impact on volatility, we believe it makes sense to consider all of these measures, in order to lend more robustness to the results.

The estimated regressions may be written as follows:

$$
\begin{gathered}
\sigma_{i t}=\alpha_{i}+\alpha_{i m} M_{t}+\sum_{j=1}^{12} \rho_{i j} \sigma_{i t-j}+\phi_{i} V_{i t}+v_{i t} \\
\sigma_{i t}=\alpha_{i}+\alpha_{i m} M_{t}+\sum_{j=1}^{12} \rho_{i j} \sigma_{i t-j}+\theta_{i} N T_{i t}+\eta_{i t} \\
\sigma_{i t}=\alpha_{i}+\alpha_{i m} M_{t}+\sum_{j=1}^{12} \rho_{i j} \sigma_{i t-j}+\gamma_{i} A T S_{i t}+\tau_{i t}
\end{gathered}
$$

where $\sigma_{i t}$ is the value on day $t$ of each of the volatility measures considered, where $i$ can take ten different values; $M_{t}$ is a dummy variable that takes a value of 1 for Mondays and zero for the remaining days of the week; V, NT and ATS are the volume measures described above; $v_{i t}, \eta_{i t}$ and $\tau_{i t}$, the residuals of the regressions, are the new volatility series after the removal of Monday and volume effects which, if present, are captured by the coefficients of the variables in question.

Table VI gives the coefficients of the volume proxies used in expressions (9), (10) and (11). Similar results are found for the first two volume measures considered. 
When the variable included in the regression is volume traded in Euros, it can be seen to have a positive influence on volatility for all the measures of historical volatility. Similarly, when trading volume is measured in terms of the number of trades, it is also observed to have a significantly positive effect on volatility in all the terms in which it was measured. However, when volume is measured in terms of average trade size, all the significant effects of volume on volatility $\left(\left|\varepsilon_{\mathrm{AA}}\right|,\left|\varepsilon_{\mathrm{CA}}\right|\right.$, realized volatility and ST implied volatility) that emerge are negative. In other words, volatility increases with increases in volume traded, but decreases with increases in trade size. Both Easley and O'Hara (1987) and Admati and Pfeiderer (1988) suggest that informed traders engage in higher volume trading than uninformed traders do. Thus, the larger observed trade size, the higher the amount of informed trading and therefore the less volatility we can expect to find in the market, Hellwig (1980) or Wang $(1993)^{14}$.

\subsection{2- The effect of herding on volatility.}

Having obtained the "clean" volatility series, we can now examine them to determine the extent of the linear effect of herding intensity on calculated volatility on day $t$.

To do so we run the following regressions:

$$
\begin{aligned}
& v_{i t}=\omega_{i t}+\delta_{i t} H_{i s t}+\lambda_{i t} \\
& \eta_{i t}=\omega_{i t}+\delta_{i t} H_{i s t}+\lambda_{i t} \\
& \tau_{i t}=\omega_{i t}+\delta_{i t} H_{i s t}+\lambda_{i t}
\end{aligned}
$$

where $v_{i t}, \eta_{i t}$ and $\tau_{i t}$ are the residuals of the expressions (9), (10) and (11), $\omega_{i t}$ is a constant and $H_{i s t}$ is the PS(2006) herding intensity measure on day $t$, where $s$ can take three different values, according to whether the herding has occurred during an up run, a down run or a zero run.

Table VII shows the coefficients for the different measures of herding intensity ( $\mathrm{Ha}, \mathrm{Hb}$ and $\mathrm{Hc}$ ). Overall, we find all three types of herding to have a significantly negative effect on all the volatility measures except implied volatility. Such a difference in results may be explained by the relevance of the expiration effect in derivatives markets, which has not hitherto been taken into account in our models. Hence, we

\footnotetext{
${ }^{14}$ Nevertheless, despite the observed differences across the three volume measures considered, if we focus on the adjusted $\mathrm{R}^{2}$, we find no major differences between V, NT and ATS within each volatility measure.
} 
include an additional dummy variable in equations referring to implied volatility, taking value 1 on the expiration date of Ibex-35 derivatives contracts and zero otherwise. The results, namely ST ATM Call*, are shown at the end of Table VII. On including such a modification, implied volatility is also influenced by Ha and Hc. It should be noted that buying pressure is more likely to affect call options demand and its implied volatility than selling pressure.

Given that the level of herding intensity increases as $\mathrm{H}_{\mathrm{s}}$ becomes more negative, the negative coefficients found for the herding intensity variable in regressions (12), (13) and (14) suggest that stocks exhibiting higher levels of herding intensity will also present higher volatility. Our results are consistent with those of Venezia, Nashikkar and Shapira (2009) given that they also find a direct relationship between herding and market volatility. In addition, if we identify herd trading with a type of uninformed trading, our results are consistent with those indicating that uninformed trading drive volatility (Hellwig [1980] and Wang [1993] or Froot, Scharfstein and Stein [1992], Avramov, Chordia and Goyal [2006]). The results for the measures of historical and realized volatility are very similar, irrespective of which volume proxy is used, and also unanimous. The variable used to measure herding intensity appears to affect the volatility generated that day, the effect being observed in practically all the volatility measures based on stock market data ${ }^{15}$.

Overall, the results for the measures of historical and realized volatility show that a higher level of herding (which might be interpreted as uninformed trading) leads to greater price changes (volatility), that is, less stability. Herding traders either add momentum to price changes or cause prices to overshoot the fundamental price, resulting in more volatile and, perhaps, less informative prices. Nevertheless, these traders also provide liquidity to markets

The differences found between the results for implied volatility and the rest of the measures used in the analysis deserve some particular comments. First, it is worth noting the difference in the results in including the expiration date as an explanatory variable in eq 12-14. The most frequent interpretation of implied volatility is as the market's future volatility forecast. Implied volatility mainly gathers together expectations about factors such as market price, fear of sharp drops or interest rates which, in turn, depend on future information. The option prices, and therefore the

\footnotetext{
${ }^{15}$ There are some exceptions, certain types of herding do not impact significantly on volatility captured by $\left|\varepsilon_{\mathrm{AA}}\right|, \sigma_{\mathrm{R}-\mathrm{AC}}, \sigma_{\mathrm{R}-\mathrm{AA}}$ and $\sigma_{\mathrm{GK}}$.
} 
implied volatility estimates, also involve other factors such as the expiration date, the strike price, the bearish/bullish state of the market, liquidity problems in the options traded, volatility price skews due to buy/sell fees, excessive leverage effects or wide bid/ask spreads (see, among others, Peña, Rubio and Serna (1999) or Serna (2004). In the absence of the expiration effect, herd behaviour does not affect, by definition, the implied volatility. That is, expectations on future price changes do not account for unknown factors that have not yet been proved relevant. Nevertheless, when the expiration effect is considered, traders are conscious of the large amount of informative factors influencing decision making and therefore uninformed traders find it useful to imitate the decision of other traders that are thought to be better informed. This result suggests that imitative behavior increases on expiration dates as stated in Blasco, Corredor and Ferreruela (2009b).

Second, our findings show that implied volatility, when estimated from ATM call options and the expiration effect is taken into account, is influenced by buyer initiated and zero tick herding. This result may indicate that options market participants, who are thought to be better informed than spot market participants, tend to expect higher future volatility when they suspect that the stock market fluctuates under a significant influence of uninformed traders. This attitude of option traders is compatible with the learning hypothesis described in Bollen and Whaley (2004). Our results using short-term implied volatility provide new information that has not been presented in former studies.

Finally, in order to detect whether the herding caused in the small capitalization stocks influences volatility as the large capitalization stocks do, we carry out an additional analysis. We repeat the previous tests with the small cap and large cap indexes. We want to assess how much the herding effect in those indexes affects the volatility of the Ibex-35. The results presented in Table VIII, Panel A and B mainly support our previous findings: herding influences volatility, especially when the volume effects are cleared using trading volume or trade size and we consider larger capitalization stocks. In conclusion, we find that the phenomenon of imitative behaviour increases market volatility and, therefore, herding may be considered an additional risk factor. Our results may be explained, among other factors, by the percentage of institutional ownership in the Ibex-35 firms, given that institutional ownership is highly correlated with size. In our particular case, the Spanish market, the average percentage of institutional ownership for the stocks included in the large cap index is $28.31 \%$ (this 
value increases to $31.70 \%$ if BBVA is not included) whereas those included in the small cap index exhibit an average percentage of institutional ownership of $15.09 \%{ }^{16}$. According to Dennis and Strickland (2002), institutional shareholders react strongly to large market price changes by herding together and moving prices. Institutional managers are often evaluated on their short-term performance and have a strong incentive to herd in order to avoid the cost of unfavorable deviations from the consensus. Christoffersen and Tang (2009), similarly to Barber, Odean, and Zhu (2009), find that institutional traders are more likely to herd than retail or small investors. Their empirical results strongly support the theoretical predictions of Avery and Zemsky (1998) about information cascades. These phenomena are present in daily trading, and herding can destabilize prices in stocks where information in trading is normally of high quality, which is the case with large firms, although the price instability is not longlived.

Verma and Verma (2007), in turn, suggest that individual investor sentiment reacts to institutional investor sentiment and that a significant negative relation exists between irrational sentiment and volatility. Then, if both individual and institutional investors feel worried about a large market price change, their sentiment and incentive to herd may cause increases in market volatility. The results are likely to be due to both investment criteria. We believe that our study contributes to the robustness and novelty of the herding literature through the number of volatility measures and types of volume considered and the explicit use of a measure of intraday herding.

\subsection{3- Non-linear causality}

Since the relationships between variables may be linear and/or non-linear, we also test for possible non-linear causality between the different measures of volatility and the herding level. Using the procedure described in Hiemstra and Jones (1994), we find no evidence at all of non-linear causality in the results.

A different pattern emerges, however, in the results for implied volatility in the prices of call ATM options. The values of the statistic are positive but non-significant at the standard levels of significance and higher when the cause variable is sell-side

\footnotetext{
${ }^{16}$ Data have been extracted from the data base SABI (Sistema de Análisis y Balances Ibéricos) and BankScope and refer to the significant ownership information that was notified to the Spanish stock market national commission (CNMV) in 2003. Prior data are not available. The CNMV is aimed at supervising and inspecting the Spanish Stock Markets and the activities of all the participants in the market.
} 
herding. This positive sign is robust to different values of the parameters in the Hiemstra and Jones (1994) procedure. For the remaining volatility measures, the sign of the non-linear causality statistic is negative, which is a clear indication that the herding level hampers, rather than facilitates, the prediction of non-linear volatility. This difference in the direction of the results could be interpreted as the already mentioned conceptual difference between the various volatility measures and as being somewhat coherent with the different sign (positive) of the coefficients for the linear effect of the intensity of sell-side herding on the implied volatility. For ease of reading, the results tables are not presented ${ }^{17}$, given the lack of significance of the results ${ }^{18}$.

\subsection{4- Usefulness of the herding measures in volatility forecasting}

Once the importance of herd behavior on the level of market volatility has been determined, the natural extension of the analysis is to assess whether this information can be useful in volatility forecasting. For this purpose we propose the comparison between two alternative types of models: (a) basic models including the variables defined in eq. 9, 10 and 11 and (b) extended models that incorporate additional variables associated with the intensity of herd behaviour. Both the basic and extended models will be estimated alternatively for each of the volume variables described (V, NT and ATS). The time interval of the data base used for the estimation process is January 1997 to June 2003. The out of sample forecasting runs from July 2003 to December 2003.

Static and dynamic predictions are calculated. Since both the basic and the expanded models require contemporary values for the variables of volume and the intensity of herding, we first need a prediction to be incorporated into the forecasting models. Given the high autocorrelation of these variables we consider autoregressive models that can be easily implemented to determine the proper values of volume traded and herding intensity on day t. It is worth noting that the relationship between the herding statistic and the trading volume variables may cause estimation problems if we include those variables simultaneously in the forecasting extended model. We propose a regression procedure for making the orthogonal correction so that only that component

\footnotetext{
${ }^{17}$ Nonetheless they are available from the authors upon request.

${ }^{18}$ The linear and non-linear analysis has been repeated adding to the volatility model the leverage effect (throughout the asset's returns). The results are similar to those presented here and are available from the authors upon request.
} 
of the herding statistic not included in the volume measure is incorporated as an independent variable in the model.

Tables IXa and IXb show the error terms for each model and type of prediction (the square root of the prediction error, the mean absolute error (MAE) and the mean absolute percentage error (MAPE)) for both the static and dynamic forecasting. The results are unanimous for all the volatility measures: when either volume or the number of transactions is considered, herding measures help to improve volatility forecasting. The only exception is the volatility computed as the residual of open to open returns after adjusting seasonality and autocorrelation. Nevertheless, when the average trade size is considered, herding measures do not contribute to obtaining lower error measures when the prediction models are implemented. In this sense, Song, Tan and Wu (2005) argue that other volume measures explain the volatility-volume relation better than the size of trades. Therefore, as a general rule, herding intensity variables may be useful for volatility forecasting when other relevant variables have also been considered. As is suggested in Stivers (2003), an adequate identification of actual volatility implies better volatility forecasting.

According to Stoll (2000), until recent years the modern finance paradigm used to rest on the abstractions of frictionless markets and the traditionally strict concept of efficient markets. Nevertheless, the study of microstructure and the theoretical development in the field of asymmetric information are promising from the point of view of improving asset pricing, asset allocation, derivatives pricing and financial risk management.

Following Bandi and Russell (2006), if asset prices can be written as the sum of efficient prices and a noise component that is induced by microstructure frictions, the variance of returns depends on the variance of the underlying efficient returns and the variance of the microstructure noise components. Whereas the variance of the efficient return process is a crucial ingredient in the practise and theory of asset valuation and risk management, herding is considered a microstructure component that can be employed to consistently estimate the microstructure noise variance containing information about the market's structure and dynamics.

It is of primary importance in the practice of portfolio and risk management to have an accurate estimate of the variances and covariance matrices for asset prices. By exploiting the considerable information potential of high frequency return data, we can improve, for example, the trading strategies of volatility timing. Fleming et al. (2001, 
2003) provide a methodology to evaluate the economic benefits of asset allocation strategies relying on volatility timing. In this context, it is necessary to know the correct component parts of volatility, the most appropriate intraday frequency and the estimation procedure that can be utilized to learn about the efficient return variance and microstructure noise variance in order to make them more predictable.

Similarly, the purpose of hedging is to minimize the risk of the portfolio. Asset risks change because new information is continuously received by the markets. Therefore, the hedge ratio should be time-varying because it depends on the conditional moments of the spot and futures returns. Hedging performance would benefit with the accurate knowledge of the volatility and covariance components.

We find in this paper that changes in the herding intensity measure may be informative about the market situation and its evolution in the near future. Given that our results indicate that the herding intensity increases in down market periods and for the most heavily traded stocks, the detection of relevant herding changes may help to predict volatility in these situations and, therefore, to improve investment decisionmaking as described before.

\section{4.- Conclusions}

This paper examines the way in which market volatility is affected by the presence of herding behavior. The relationship between investor behavior and market volatility has been examined in prior research in various financial markets, the majority of the findings supporting the idea that volatility increases with uninformed or liquidity trading. Information asymmetry can raise volatility and uninformed traders very frequently follow the market trend, buying when prices rise and selling when they fall, thus exhibiting a type of behavior that we might equate with herding.

The herding intensity measure used in this paper is that proposed by PS(2006), which is based on the information cascade models described in Bikhchandani, Hirshleifer and Welch (1992) where the intensity of herding in the market is measured in both buyer- and seller-initiated trading sequences. It is a daily measure constructed from intraday trade data, which we believe to be the most suitable data frequency for the detection of possible herding behavior among traders in the market.

We also use various measures of market volatility: absolute return residuals, historical volatility (Parkinson and Garman-Klass), realized volatility (Anderson et al, 
2001) and implied volatility. All of these are purged for possible day-of-the-week or volume effects that might confound the findings.

The results presented in this paper are consistent with prior literature in revealing a clear effect of herding on market volatility: the higher the observed level of herding intensity, the greater volatility we can expect to find. This result (which comes from linear relations) is homogeneous across two of the measures (historical and realized volatility) considered but does not apply entirely in the case of implied volatility, where the influence of the imitation effect is closely related to the expiration dates in option markets as well as what we interpret as a learning hypothesis in option traders' behavior. These results are clearly related to the different nature and meaning of the alternative volatility measures. The results of the assessing of the non-linear relations between herding and volatility indicate that there is no such relation between the said variables. The proposed forecasting models confirm the relevance of herding intensity measures for predicting future values of volatility and therefore for interpreting the concept of risk and for defining risk management strategies. If traders are able to better forecast future volatility values they will be able to improve asset pricing, asset allocation, derivatives pricing and financial risk management applications by the separate modelling, forecasting and pricing of the noise-microstructure and efficient return components of total return variability. 


\section{References}

Admati, A., Pfleiderer, P. (1988). "A Theory of Intraday Patterns: Volume and Price Variability", Review of Financial Studies, 1, 3-40.

Agrawal, A., Tandon, K. (1994). "Anomalies or Illusions?: Evidence from Stock Markets in Eighteen Countries," Journal of International Money and Finance, 13, 83-106.

Andersen, T.G., Bollerslev, T., Diebold, F.X., Ebens, H. (2000). “Great realizations,” Risk, March, 105108.

Andersen, T.G., Bollerslev, T., Diebold, F.X., Ebens, H. (2001). "The distribution of realized stock return volatility," Journal of Financial Economics, 61, 43-76.

Avery, C., Zemsky, P. (1998). "Multidimensional uncertainty and herd behavior in financial markets," American Economic Review 88(4), 724-748.

Avramov, D., Chordia, T., Goyal, A. (2006). "Liquidity and Autocorrelations in Individual Stock Returns," The Journal of Finance, 61, 5.

Baker, M., Wurgler, J. (2006). "Investor Sentiment and the Cross-Section of Stock Returns," Journal of Finance, 61(4), 1645-1680.

Banerjee, A. (1992). “A Simple Model of Herd Behavior,” Quarterly Journal of Economics, 107, 797818.

Bandi, F.M., Russell, J.R., (2006). "Separating microstructure noise from volatility”, Journal of Financial Economics 79, 655-692

Bandi, F.M., Russell, J.R. (2008). "Microstructure Noise, Realized Variance, and Optimal Sampling," Review of Economic Studies, 75 (2), 339 - 369.

Barber, B.M., Odean, T., Zhu, N. (2009). “Systematic Noise,” Journal of Financial Markets 12(4), 547569.

Beckers, S. (1981). "Standard Deviations Implied in Option Prices as Predictors of Future Stock Price Variability,” Journal of Banking and Finance, 5, 363-381.

Bikhchandani, S. Hirshleifer, D., Welch, I., (1992). "A Theory of Fads, Fashion, Custom, and Cultural Change as Informational Cascades,” Journal of Political Economy, 100, 992-1026.

Black, F. (1976), "Studies of Stock Price Volatility Changes," Proceeding of the 1976 meetings of the American Statistical Association, Business and Economical Statistics Section, 177-181.

Black, F., Scholes, M. (1973). "The Pricing of Options and Corporate Liabilities," The Journal of Political Economy, 81(3), 637-659.

Blasco, N., Ferreruela, S. (2007). "Comportamiento Imitador en el Mercado Bursátil Español: Evidencia Intradiaria," Revista de Economía Financiera, 13, 56-75.

Blasco, N., Ferreruela, S. (2008). "Testing intentional herding in familiar stocks: an experiment in an international context," The Journal of Behavioral Finance, 9 (2), 72-84.

Blasco, N., Corredor, P., Ferreruela, S. (2009a). "Generadores de comportamiento imitador en el mercado de valores español” Revista Española de Financiación y Contabilidad, 38, 142, 265-291.

Blasco, N., Corredor, P., Ferreruela, S. (2009b). "Una explicación del efecto herding desde el mercado de derivados". Revista de Economía Aplicada, forthcoming. 
Blasco, N., Corredor, P., Ferreruela, S. (2010) "Detecting intentional herding: what lies beneath intraday data in the Spanish stock market", Journal of the Operational Research Society, forthcoming.

Bollen, N.P.B., Whaley, R.E. (2004) "Does Net Buying Pressure Affect the Shape of Implied Volatility Functions?" Journal of Finance, 59 (2), 711-753Brennan, M., (1993). "Agency and asset prices," Finance Working Paper No. 6-93, UCLA.

Bouchaud, J-P., Farmer, J.D., Lillo, F. (2008) "How markets slowly digest changes in supply and demand". http://ssrn.com/abstract=1266681.

Bouchaud, J-P., Gefen, Y., Potters, M., Wyart. M. (2004) "Fluctuations and response in financial markets: The subtle nature of "random" price changes". Quantitative Finance, 4(2), 176-190.

Campbell, J.Y., Kyle, A.S. (1993). "Smart Money, Noise Trading and Stock Price Behaviour," Review of Economic Studies, 60(1), 1-34.

Chan, K., Fong, W.M. (2000). "Trade size, order imbalance, and the volatility -volume relation," Journal of Financial Economics, 57, 247-273.

Chan, K., Fong, W.M. (2006). "Realized Volatility and Transactions," Journal of Banking \& Finance, vol. 30 (7), 2063-2085.

Chang, E.C., Cheng, J.W., Khorana, A. (2000). "An examination of herd behavior in equity markets: An international perspective," Journal of Banking and Finance, 24, 1651-1679.

Christensen, B.J., Prabhala, N.R. (1998). "The Relation Between Implied and Realized Volatility," Journal of Financial Economics, 50, 125-150.

Christie, W.G., Huang, R.D. (1995). "Following the pied piper: Do individual returns herd around the market?" Financial Analysts Journal, July-August, 31-37.

Christoffersen, S.K., Tang, Y. (2009). "Institutional Herding and Information Cascades: Evidence from Daily Trades,” Working Paper, McGill University.

Cont, R., Bouchaud, J.P. (2000). "Herd behavior and aggregate fluctuations in financial markets". Macroeconomic Dynamics, 4, 170-196.

Corredor, P., Santamaría, R. (2001). "Predicción de volatilidad y precios de opciones de las opciones en el Ibex-35," Revista de Economía Aplicada, 9, 39-64.

Corredor, P, Santamaría, R. (2004) "Forecasting volatility in the Spanish option market" Applied Financial Economics, 14, 1-11.

Crépey, S. (2004) “Delta-hedging vega risk?” Quantitative Finance, 4, 5, October, 559-579

De Long, B.J., Shleifer, A., Summers, L.H., Walmann, R.J. (1990). "Positive Feedback Investment Strategies and Destabilizing rational Speculation,” Journal of Finance, 45, 379-395.

Demetrescu, M. (2007) “Volatility Clustering in High-Frequency Data: A self-fulfilling prophecy?", Economics Bulletin, 7, 15 1-8.

Demirer, R., Kutan, A. (2006). "Does herding behavior exist in Chinese stock markets?," Journal of International Financial Markets, Institutions and Money, 16(2), 123-142.

Dennis, P.J., Strickland, D. (2002). “Who blinks in volatile markets, individuals or institutions?” Journal of Finance, LVII, 5, 1923-1950.

Easley, D., O’Hara, M. (1987). "Price, Trade Size and Information in Securities Markets," Journal of Financial Economics, 19, 69-90. 
Engle, R.F. (1982). "Autoregressive Conditional Heteroscedasticity with Estimates of the Variance of United Kingdom Inflation”. Econometrica, 50 (4), 987-1007.

Epps, T.W., Epps, M.L. (1976). "The stochastic dependence of security price changes and transaction volumes: Implications for the Mixture-of-Distributions Hypothesis,” Econometrica, 44, 305-321.

Ferland, R., Lalancette, S. (2006). "Dynamics of realized volatilities and correlations: An empirical study," Journal of Banking \& Finance, 30(7), 2109-2130.

Fleming, J. (1998). "The quality of market volatility forecasts implied by S\&P 100 index option prices," Journal of Empirical Finance, 5, 317-345.

Fleming, J., Kirby, C., Ostdiek, B., (2001). “The economic value of volatility timing”. Journal of Finance $56,329-352$.

Fleming, J., Kirby, C., Ostdiek, B., (2003). "The economic value of volatility timing using 'realized volatility'. Journal of Financial Economics 67, 473-509

Fleming, J., Ostdiek, B., Whaley, R.E. (1995). "Predicting stock market volatility: A new measure," Journal of Futures Markets, 15, 265-302.

French K. (1980). "Stock Returns and the Weekend Effect,” Journal of Financial Economics, 8, 55-69.

French, K.R., Schwert, G.W., Stambaugh, R. (1987). “Expected Stock Returns and Volatility,” Journal of Financial Economics, 19, 3-29.

Friedman, M. (1953). "The Case for Flexible Exchange Rates," in Milton Friedman (ed.), Essays in Positive Economics, University of Chicago Press, Chicago, IL.

Froot, K.A., Scharfstein, D.S., Stein, J.C. (1992). "Herd on the Street: Informational Inefficiencies in a Market with Short-Term Speculation,” Journal of Finance, 47, 1461-1484.

Gallant, R.A., Rossi, P.E., Tauchen, G. (1992). “Stock prices and volume,” Review of Financial Studies, $5,199-242$.

Garman, M., Klass, M. (1980). "On the estimation of security price volatilities from historical data," Journal of Business, 53, 67-78.

Giot, P. (2005). "Implied volatility indexes and daily Value-at-Risk models," Journal of Derivatives, 12, 54-64.

Gompers, P.A., Metrick, A. (2001). "Institutional Investors and Equity Prices," Quarterly Journal of Economics, 116(1), 229-259.

Hellwig, M.F. (1980). "On the Aggregation of Information in Competitive Markets," Journal of Economic Theory, 22, 477-498.

Henker, J., Henker T., Mitsios A. (2006). "Do Investors Herd Intraday in Australian Equities?," International Journal of Managerial Finance, 2 (3), 196.

Hiemstra, C., Jones, J.D. (1994). "Testing for linear and nonlinear Granger causality in the stock pricevolume relation". Journal of Finance 49, 5, 1639-1664.

Hirshleifer, D., Subrahmanyam, A., Titman, S. (1994). "Security Analysis and Trading Patterns When Some Investors Receive Information before Others,” Journal of Finance, 49(5), 1665-1698.

Hwang, S., Salmon, M. (2004). “Market stress and herding”, Journal of Empirical Finance, 11, 585-616.

Jones, C.M., Kaul, G., Lipson, M.L. (1994). “Transactions, volume, and volatility,” Review of Financial Studies 7, 631-651. 
Karpoff, J.M. (1987). "The relation between price changes and trading volume: A survey," Journal of Financial and Quantitative Analysis, 22, 109-126.

Keim, D.B., Stambaugh, F. (1984). “A further investigation of weekend effects in stock returns,” Journal of Finance, 39, 819-840.

La Spada, G., Farmer, J.D., Lillo, F. (2008). "The non-random walk of stock prices: the lonf-term correlation between signs and sizes". The European Physical Journal B. DOI:10.1140/epjb/e200800244-4.

Lakonishok, J., Shleifer, A., Vishny, R.W. (1992). "The impact of institutional trading on stock prices," Journal of Financial Economics, 32, 23-43.

Lamoureux, C. G., Lastrapes, W. D. (1990). "Heteroskedasticity in Stock Return Data: Volume versus GARCH Effects,” Journal of Finance, 45(1), 221-229.

Lillo, F., Esteban, M., Vaglica, G., Mantegna, R.N. (2008). "Specialization and herding behavior of trading firms in a financial market," New Journal of Physics, 10, 1-15.

Lillo, F., Farmer, J. D. (2004). "The long memory of the efficient market". Studies in Nonlinear Dynamics \& Econometrics, 8(3), Article 1, 1-15.

Lin, W., Tsai, S., Sun, D. (2010). “What Causes Herding: Information Cascade or Search Cost?"MPRA Paper

Maug, E., Naik, N. (1996). "Herding and delegated portfolio management," mimeo, London Business School.

Merton, R. C. (1980). "On Estimating the Expected Return on the Market: An Exploratory Investigation," Journal of Financial Economics, 8, 323-361.

O’Hara, M. 1995 “Market Microstructure Theory”. Blackwell, UK.

Palomino, F. 1996. Noise trading in small Markets, Journal of Finance 51(4): 1537-1550.

Patell, J.M., Wolfson, M.A. (1981). "The Ex Ante and Ex Post Price Effect of Quarterly Earnings Announcements Reflected in Option and Stock Prices," Journal of Accounting Research, 19, 117-140.

Patterson, D.M., Sharma, V. (2006). "Do Traders Follow Each Other at the NYSE?" Working Paper, University of Michigan-Dearborn.

Parkinson, M. (1980). "The extreme value method for estimating the variance of the rate of return," Journal of Business, 53, 61-68.

Peña, I.; Rubio, G.; Serna, G. (1999): Why do we smile? On the determinants of the implied volatility function. Journal of Banking and Finance, 23, 1151-1179

Puckett, A., Yan, X. (2007). "The Determinants and Impact of Short-Term Institutional Herding," Working Paper. Available at SSRN.

Radalj, M., McAleer, M. (1993). "Herding, information cascades and volatility spillovers in futures markets," Working Paper, University of Western Australia, Perth,

Rajan, R.G. (1994). "Why credit policies fluctuate: A theory and some evidence," Quarterly Journal of Economics, 436, 399-442.

Roll, R. (1992). “A mean/variance analysis of tracking error,” Journal of Portfolio Management, summer, 13-22. 
Scharfstein, D.S., Stein, J.C. (1990). "Herd behavior and investment," American Economic Review, vol. $80,465-479$.

Schwert, G.W. (1989). "Why Does Stock Market Volatility Change Over Time?" Journal of Finance, 44, $1115-1153$.

Serna, G. (2004) La sonrisa de la volatilidad en los mercados de opciones. Bolsa de Madrid. 128. Pp. 34 37

Shefrin, H. (2000). "Beyond greed and fear; Understanding behavioral finance and the psychology of investing," Cambridge: HBS Press.

Sias, R.W. 2004. Institutional Herding. Review of Financial Studies 17(1): 165-206.

Simon, D.P. (2003). "The Nasdaq Volatility Index During and After the Bubble," Journal of Derivatives, $11(2), 9-22$.

Song, F., Tan, H., Wu, Y. (2005). "Trade size, trade frequency, and the volatility-volume relation" The Journal of Risk Finance, 6 (5), 424-437.

Stivers C.T. (2003). "Firm-level return dispersion and the future volatility of aggregate stock market returns" Journal of Financial Markets, 6, 389-411.

Stoll, H.R. (2000). Friction. Journal of Finance, 55, 1479-1514.

Thaler, R. (1991). “Quasi-rational economics,” New York: Russell Sage Foundation.

Trueman, B. (1994). “Analyst Forecasts and herding behaviour," Review of Financial Studies, 7, 97-124.

Venezia, I., Nashikkar, A.J., Shapira, Z.(2009), "Herding in Trading by Amateur and Professional Investors", Working paper, New York University.

Verma, R., Verma, P. (2007). "Noise trading and stock market volatility", Journal of Multinational Financial Management 17, 3, 231-243.

Wang, J. (1993). "A Model of intertemporal asset prices under asymmetric information," Review of Economic Studies, 60, 249-282.

Wermers, R. (1999). "Mutual fund herding and the impact on stock prices", Journal of Finance, 54, 581622. 


\section{TABLES}

Table I. Descriptive data for the herding measures across up, down and zero runs. Descriptive statistics for the Ibex35, Small Cap Index and Large Cap Index.

\begin{tabular}{lcccrrrrrr}
\hline & \multicolumn{3}{c}{ Ibex35 } & \multicolumn{4}{c}{ Small cap Index } & \multicolumn{3}{c}{ Large cap index } \\
& \multicolumn{1}{c}{$\mathrm{Ha}$} & \multicolumn{1}{c}{$\mathrm{Hb}$} & \multicolumn{1}{c}{$\mathrm{Hc}$} & \multicolumn{1}{c}{$\mathrm{Ha}$} & \multicolumn{1}{c}{$\mathrm{Hb}$} & \multicolumn{1}{c}{$\mathrm{Hc}$} & \multicolumn{1}{c}{$\mathrm{Ha}$} & \multicolumn{1}{c}{$\mathrm{Hb}$} & \multicolumn{1}{c}{$\mathrm{Hc}$} \\
\hline Mean & -8.81 & -8.72 & -4.03 & -6.57 & -6.43 & -2.69 & -17.43 & -17.29 & -9.59 \\
Median & -8.89 & -8.77 & -3.97 & -6.44 & -6.25 & -2.44 & -17.37 & -17.14 & -9.07 \\
St. Dev. & 2.12 & 2.14 & 1.38 & 2.31 & 2.31 & 1.59 & 4.46 & 4.51 & 3.85 \\
Asymmetry & 0.10 & 0.00 & -0.26 & -0.16 & -0.24 & -0.57 & -0.46 & -0.58 & -1.11 \\
Kurtosis & -0.37 & -0.27 & -0.35 & 3.59 & 3.06 & 6.50 & 2.71 & 2.74 & 2.99 \\
Minimum & -14.36 & -15.59 & -8.92 & -19.13 & -19.84 & -15.10 & -34.32 & -34.33 & -24.30 \\
Maximum & -1.08 & -1.54 & 0.22 & 0.63 & -0.34 & 1.03 & -3.03 & -3.90 & -1.09 \\
\hline
\end{tabular}

Bootstrap critical value for $\mathrm{Ha}$ at the $1 \%$ significance level: -2.20

Bootstrap critical value for $\mathrm{Hb}$ at the $5 \%$ significance level: -2.16

Bootstrap critical value for Hc at the $10 \%$ significance level: -2.01

Table II: Results for the SUR estimation (Seemingly Unrelated Regression) of the herding intensity on the market situation and the trading volume. ${ }^{* * *}$ denotes significance at $1 \%,{ }^{* *}$ denotes significance at $5 \%$ and ${ }^{*}$ denotes significance at $10 \%$. Volume coefficients are multiplied by $10^{7}$. Estimated models:
(a) $\quad H_{a t}=\alpha_{a 0}+\delta_{a j} \sum_{j=1}^{k} H_{a t-j}+\alpha_{a 1} D_{d t}\left(V_{t}\right)+u_{a t}$
(b) $\quad H_{b t}=\alpha_{b 0}+\delta_{b j} \sum_{j=1}^{k} H_{b t-j}+\alpha_{b 1} D_{d t}\left(V_{t}\right)+u_{b t}$
(c) $\quad H_{c t}=\alpha_{c 0}+\delta_{c j} \sum_{j=1}^{k} H_{c t-j}+\alpha_{c 1} D_{d t}\left(V_{t}\right)+u_{c t}$

\begin{tabular}{lccc}
\hline & $(\mathrm{a})$ & $(\mathrm{b})$ & $(\mathrm{c})$ \\
$\mathrm{D}_{\text {down }}$ & -0.1396 & -0.1441 & -0.0483 \\
t-stat. & $(-2.15)^{* *}$ & $(-2.15)^{* * *}$ & $(-1.07)$ \\
& & & -0.0140 \\
Volume & -0.0305 & -0.0337 & $(-6.12)^{* *}$ \\
t-stat. & $(-8.82)^{* *}$ & $(-9.57)^{* *}$ & \\
\hline
\end{tabular}


Table III. Descriptive data for the different volatility measures considered

\begin{tabular}{|c|c|c|c|c|c|c|c|c|c|}
\hline & $\left|\varepsilon_{\mathrm{AA}}\right|$ & $\left|\varepsilon_{\mathrm{AC}}\right|$ & $\left|\varepsilon_{\mathrm{CC}}\right|$ & $\left|\varepsilon_{\mathrm{CA}}\right|$ & $\sigma_{R-A C}$ & $\sigma_{R-A A}$ & $\sigma_{P}$ & $\sigma_{G K}$ & $\begin{array}{l}S T \\
\text { ATM } \\
\text { Call }\end{array}$ \\
\hline Mean & 0.0129 & 0.0108 & 0.0122 & 0.0061 & 0.0120 & 0.0142 & 0.0120 & 0.0117 & 0.0165 \\
\hline Median & 0.0101 & 0.0087 & 0.0096 & 0.0045 & 0.0107 & 0.0125 & 0.0105 & 0.0103 & 0.0160 \\
\hline St. Dev. & 0.0126 & 0.0091 & 0.0104 & 0.0071 & 0.0059 & 0.0081 & 0.0065 & 0.0061 & 0.0065 \\
\hline Asymmetry & 3.8175 & 2.0839 & 1.6419 & 7.8360 & 2.9336 & 6.3570 & 2.4582 & 2.3132 & 0.0493 \\
\hline Kurtosis & 34.1569 & 10.8448 & 3.8602 & 135.7490 & 18.1877 & 94.9509 & 11.3010 & 10.1018 & 1.7191 \\
\hline Minimum & 0.0000 & 0.0000 & 0.0000 & 0.0000 & 0.0030 & 0.0034 & 0.0022 & 0.0020 & 0.0000 \\
\hline Maximum & 0.1898 & 0.1118 & 0.0694 & 0.1588 & 0.0787 & 0.1744 & 0.0687 & 0.0693 & 0.0411 \\
\hline
\end{tabular}

Table IV. Correlation between the different volatility measures considered

\begin{tabular}{|c|c|c|c|c|c|c|c|c|c|}
\hline & $\left|\varepsilon_{A A}\right|$ & $\left|\varepsilon_{A C}\right|$ & $\left|\varepsilon_{C C}\right|$ & $\left|\varepsilon_{C A}\right|$ & $\sigma_{R-A C}$ & $\sigma_{R-A A}$ & $\sigma_{P}$ & $\sigma_{G K}$ & $\begin{array}{l}S T \\
\text { ATM } \\
\text { Call }\end{array}$ \\
\hline$\left|\varepsilon_{A A}\right|$ & 1.0000 & & & & & & & & \\
\hline$\left|\varepsilon_{A C}\right|$ & 0.2767 & 1.0000 & & & & & & & \\
\hline$\left|\varepsilon_{C C}\right|$ & 0.5861 & 0.3070 & 1.0000 & & & & & & \\
\hline$\left|\varepsilon_{C A}\right|$ & 0.2452 & 0.6986 & 0.3485 & 1.0000 & & & & & \\
\hline$\sigma_{R-A C}$ & 0.5642 & 0.5376 & 0.4678 & 0.4061 & 1.0000 & & & & \\
\hline$\sigma_{R-A A}$ & 0.6764 & 0.5021 & 0.8076 & 0.4492 & 0.8794 & 1.0000 & & & \\
\hline$\sigma_{P}$ & 0.4177 & 0.7536 & 0.3727 & 0.5552 & 0.8167 & 0.7114 & 1.0000 & & \\
\hline$\sigma_{G K}$ & 0.4313 & 0.5271 & 0.3479 & 0.4039 & 0.8638 & 0.7261 & 0.8962 & 1.0000 & \\
\hline $\begin{array}{c}\text { ST ATM } \\
\text { Call }\end{array}$ & 0.3100 & 0.3107 & 0.3137 & 0.3043 & 0.5305 & 0.4997 & 0.4490 & 0.4847 & 1.0000 \\
\hline
\end{tabular}


Table V. Correlation between the different trade volume measures. The data shown are the coefficients of correlation between daily trading volume in $(V)$, number of trades $(N T)$ and trade size in Euros (ATS) for Ibex-35 stocks.

\begin{tabular}{cccc}
\hline & $V$ & $N T$ & $A T S$ \\
\hline$V$ & 1.0000 & & \\
$N T$ & 0.8149 & 1.0000 & \\
$A T S$ & 0.3301 & -0.2256 & 1.0000 \\
\hline
\end{tabular}

Table VI. Coefficients for the trade volume measures. The data shown are the coefficients for the trading volume proxies in the following regressions:

$$
\begin{aligned}
& \sigma_{i t}=\alpha_{i}+\alpha_{i m} M_{t}+\sum_{j=1}^{12} \rho_{i j} \sigma_{i t-j}+\phi_{i} V_{i t}+v_{i t} \\
& \sigma_{i t}=\alpha_{i}+\alpha_{i m} M_{t}+\sum_{j=1}^{12} \rho_{i j} \sigma_{i t-j}+\theta_{i} N T_{i t}+\eta_{i t} \\
& \sigma_{i t}=\alpha_{i}+\alpha_{i m} M_{t}+\sum_{j=1}^{12} \rho_{i j} \sigma_{i t-j}+\gamma_{i} A T S_{i t}+\tau_{i t}
\end{aligned}
$$

where $\sigma_{\text {it }}$ is the value on day $t$ of each of the volatility measures considered, where $i$ can take ten different values, $M_{t}$ is a dummy variable that takes a value of 1 for Mondays and 0 the remaining days of the week, $V$ is volume traded in Euros, $N T$ is volume traded in number of trades and ATS is average trade

\begin{tabular}{|c|c|c|c|c|}
\hline & & $V$ & $N T$ & $A T S$ \\
\hline \multirow[t]{3}{*}{$\left|\varepsilon_{\mathrm{AA}}\right|$} & Coeff. & $0,0027^{* * *}$ & $0.0041^{* * *}$ & $-0.0000^{* *}$ \\
\hline & $t$-stat. & $(4.25)$ & $(5.88)$ & $(-2.35)$ \\
\hline & Adj. $R^{2}$ & 0.1159 & 0.1268 & 0.1074 \\
\hline \multirow[t]{3}{*}{$\left|\varepsilon_{\mathrm{AC}}\right|$} & Coeff. & $0.0030^{* * *}$ & $0.0036^{* * *}$ & -0.0000 \\
\hline & t-stat. & $(7.95)$ & $(8.33)$ & $(-0.51)$ \\
\hline & $\operatorname{Adj} . R^{2}$ & 0.1237 & 0.1296 & 0.0994 \\
\hline \multirow[t]{3}{*}{$\left|\varepsilon_{\mathrm{CC}}\right|$} & Coeff. & $0.0033^{* * *}$ & $0.0035^{* * *}$ & 0.0000 \\
\hline & $t$-stat. & (7.49) & (7.19) & $(0.41)$ \\
\hline & Adj. $R^{2}$ & 0.1520 & 0.0097 & 0.1291 \\
\hline \multirow{3}{*}{$\left|\varepsilon_{\mathrm{CA}}\right|$} & Coeff. & $0.0012^{* * *}$ & $0.0016^{* * *}$ & $-0.0000^{*}$ \\
\hline & $t$-stat. & (3.36) & (4.14) & $(-1.82)$ \\
\hline & Adj. $R^{2}$ & 0.1165 & 0.1204 & 0.1111 \\
\hline \multirow[t]{3}{*}{$\sigma_{R-A C}$} & Coeff. & $0.0018^{* * *}$ & $0.0024^{* * *}$ & $-0.0000^{* *}$ \\
\hline & t-stat. & $(9.42)$ & (10.87) & $(-2.18)$ \\
\hline & Adj. $R^{2}$ & 0.4900 & 0.5005 & 0.4712 \\
\hline \multirow[t]{3}{*}{$\sigma_{R-A A}$} & Coeff. & $0.0023^{* * *}$ & $0.0029^{* * *}$ & $-0.0000^{* *}$ \\
\hline & $t$-stat. & $(8.05)$ & $(9.32)$ & $(-2.50)$ \\
\hline & $\operatorname{Adj} . R^{2}$ & 0.4073 & 0.4154 & 0.3911 \\
\hline \multirow[t]{3}{*}{$\sigma_{P}$} & Coeff. & $0.0025^{* * *}$ & $0.0029^{* * *}$ & -0.0000 \\
\hline & $t$-stat. & $(10.52)$ & $(10.93)$ & $(-0.35)$ \\
\hline & $\operatorname{Adj.} R^{2}$ & 0.3712 & 0.3779 & 0.3409 \\
\hline \multirow[t]{3}{*}{$\sigma_{G K}$} & Coeff. & $0.0022^{* * *}$ & $0.0027^{* * *}$ & -0.0000 \\
\hline & $t$-stat. & $(9.60)$ & $(10.38)$ & $(-0.77)$ \\
\hline & Adj. $R^{2}$ & 0.3968 & 0.4053 & 0.3656 \\
\hline \multirow[t]{3}{*}{ ST ATM Call } & Coeff. & 0.0000 & $0.0004^{*}$ & $-0.0000^{* * * *}$ \\
\hline & t-stat. & $(-0.10)$ & $(1.78)$ & $(-3.09)$ \\
\hline & Adj. $R^{2}$ & 0.6457 & 0.6466 & 0.6486 \\
\hline
\end{tabular}
size. The values shown in parentheses are the t-statistics.

${ }^{* * * *}$ denotes significance at $1 \%,{ }^{* *}$ denotes significance at $5 \%$ and ${ }^{*}$ denotes significance at $10 \%$. 
Table VII. Results of herding on the volatility measures of the Ibex-35. The data shown are the coefficients for the effect of the herding intensity measures on the volatility measures purged of volume effects and sorted by type of volume measure, where $v_{i t}$ is the volatility measure after removing the volume variable $V$, $\eta_{i t}$ is the volatility measure after removing the volume variable $N T$ and $\tau_{i t}$ is the volatility measure with ATS removed. ST ATM Call* indicates the coefficients corresponding to herding intensity when implied volatility is additionally explained by the Dummy variable relative to the expiration date of the derivatives market. The expressions of the regressions are as follows:

$$
v_{i t}=\omega_{i t}+\delta_{i t} H_{i s t}+\lambda_{i t}, \quad \eta_{i t}=\omega_{i t}+\delta_{i t} H_{i s t}+\lambda_{i t} \quad \tau_{i t}=\omega_{i t}+\delta_{i t} H_{i s t}+\lambda_{i t}
$$

The values in parentheses are the t-statistics. ${ }^{* * *}$ denotes significance at $1 \%,{ }^{* *}$ denotes significance at $5 \%$ and ${ }^{*}$ denotes significance at $10 \%$.

\begin{tabular}{|c|c|c|c|c|c|c|c|c|c|}
\hline & \multicolumn{3}{|c|}{$v$} & \multicolumn{3}{|c|}{$\eta$} & \multicolumn{3}{|c|}{$\tau$} \\
\hline & $H a$ & $H b$ & $H c$ & $H a$ & $H b$ & $H c$ & $H a$ & $H b$ & $H c$ \\
\hline \multirow[t]{2}{*}{$\left|\varepsilon_{\mathrm{AA}}\right|$} & $-0.0003^{* *}$ & $-0.0003^{* *}$ & $-0.0006^{* *}$ & -0.0001 & -0.0001 & -0.0004 & $-0.0007^{* * * *}$ & $-0.0006^{* * * *}$ & $-0.0010^{* * * *}$ \\
\hline & $(-2.30)$ & $(-2.01)$ & $(-2.34)$ & $(-0.52)$ & $(-0.45)$ & $(-1.51)$ & $(-5.24)$ & $(-4.79)$ & $(-3.78)$ \\
\hline \multirow[t]{2}{*}{$\left|\varepsilon_{\mathrm{AC}}\right|$} & $-0.0004^{* * *}$ & $-0.0004^{* * *}$ & $-0.0008^{* * *}$ & $-0.0003^{* * *}$ & $-0.0003^{* * *}$ & $-0.0007^{* * *}$ & $-0.0009^{* * * *}$ & $-0.0008^{* * * *}$ & $-0.0013^{* * * *}$ \\
\hline & $(-4.34)$ & $(-3.83)$ & $(-4.67)$ & $(-3.31)$ & $(-2.97)$ & $(-4.09)$ & $(-8.61)$ & $(-7.90)$ & $(-7.10)$ \\
\hline \multirow[t]{2}{*}{$\left|\varepsilon_{\mathrm{CC}}\right|$} & $-0.0005^{* * *}$ & $-0.0004^{* * *}$ & $-0.0010^{* * * *}$ & $-0.0005^{* * *}$ & $-0.0004^{* * *}$ & $-0.0014^{* * * *}$ & $-0.0010^{* * * *}$ & $-0.0008^{* * * *}$ & $-0.0015^{* * * *}$ \\
\hline & $(-4.43)$ & $(-3.85)$ & $(-5.87)$ & $(-4.04)$ & $(-3.55)$ & $(-5.64)$ & $(-8.62)$ & $(-7.49)$ & $(-8.18)$ \\
\hline \multirow[t]{2}{*}{$\left|\varepsilon_{\mathrm{CA}}\right|$} & $-0.0004^{* * * *}$ & $-0.0002^{* * *}$ & $-0.0008^{* * * *}$ & -0.0003 & $-0.0003^{* * *}$ & $-0.0007^{* * *}$ & $-0.0008^{* * * *}$ & $-0.0008^{* * * *}$ & $-0.0012^{* * *}$ \\
\hline & $(-4.43)$ & $(-3.80)$ & $(-4.66)$ & $(-1.19)$ & $(-2.97)$ & $(-4.09)$ & $(-8.68)$ & $(-7.91)$ & $(-7.10)$ \\
\hline \multirow{2}{*}{$\sigma_{R-A C}$} & $-0.0002^{* * *}$ & $-0.0001^{*}$ & $-0.0002^{* *}$ & $-0.0001^{* * *}$ & 0.0000 & -0.0001 & $-0.0005^{* * * *}$ & $-0.0003^{* * * *}$ & $-0.0005^{* * *}$ \\
\hline & $(-4.56)$ & $(-1.63)$ & $(-2.42)$ & $(-2.63)$ & $(0.12)$ & $(-1.42)$ & $(-9.76)$ & $(-6.60)$ & $(-5.01)$ \\
\hline \multirow{2}{*}{$\sigma_{R-A A}$} & $-0.0003^{* * *}$ & $-0.0002^{* *}$ & $-0.0005^{* *}$ & $-0.0002^{* *}$ & -0.0001 & $-0.0004^{*}$ & $-0.0006^{* * *}$ & $-0.0005^{* * *}$ & $-0.0008^{* * *}$ \\
\hline & $(-4.07)$ & $(-2.13)$ & $(-2.55)$ & $(-2.45)$ & $(-0.75)$ & $(-1.96)$ & $(-8.94)$ & $(-6.52)$ & $(-4.28)$ \\
\hline \multirow[t]{2}{*}{$\sigma_{P}$} & $-0.0003^{* * *}$ & $-0.0002^{* * *}$ & $-0.0005^{* * *}$ & $-0.0003^{* * *}$ & $-0.0001^{* *}$ & $-0.0004^{* * * *}$ & $-0.0007^{* * * *}$ & $-0.0005^{* * *}$ & $-0.0008^{* * *}$ \\
\hline & $(-5.28)$ & $(-3.26)$ & $(-4.50)$ & $(-4.08)$ & $(-2.19)$ & $(-3.80)$ & $(-10.86)$ & $(-8.82)$ & $(-7.66)$ \\
\hline \multirow[t]{2}{*}{$\sigma_{G K}$} & $-0.0003^{* * *}$ & $-0.0001^{*}$ & $-0.0003^{* * *}$ & $-0.0002^{* * *}$ & -0.0000 & $-0.0002^{* *}$ & $-0.0006^{* * * *}$ & $-0.0004^{* * *}$ & $-0.0006^{* * * *}$ \\
\hline & $(-4.54)$ & $(-1.78)$ & $(-2.94)$ & $(-3.11)$ & $(-0.42)$ & $(-1.98)$ & $(-9.77)$ & $(-7.15)$ & $(-6.30)$ \\
\hline \multirow[t]{2}{*}{ ST ATM Call } & -0.0001 & 0.0000 & -0.0000 & -0.0000 & 0.0001 & 0.0001 & -0.0001 & 0.0000 & -0.0000 \\
\hline & $(-1.59)$ & $(0.04)$ & $(-0.25)$ & $(-0.19)$ & $(1.33)$ & $(0.64)$ & $(-1.28)$ & $(0.25)$ & $(-0.11)$ \\
\hline \multirow[t]{2}{*}{ ST ATM Call } & $-0.0001^{* * *}$ & -0.0000 & $-0.0001^{*}$ & $-0.0001^{*}$ & 0.0000 & $-0.0001^{*}$ & $-0.0001^{* * *}$ & -0.0000 & -0.0000 \\
\hline & $(-3.45)$ & $(-1.23)$ & $(-1.69)$ & $(-1.73)$ & $(0.37)$ & $(-1.69)$ & $(-3.00)$ & $(-0.92)$ & $(-1.46)$ \\
\hline
\end{tabular}


Table VIII. Panel A. Influence of herding in small cap on the volatility measures of the Ibex-35 index. The data shown are the coefficients for the effect of the herding intensity measures on the volatility measures purged of volume effects and sorted by type of volume measure, where $v_{i t}$ is the volatility measure after removing the volume variable $V, \eta_{i t}$ is the volatility measure after removing the volume variable $N T$ and $\tau_{i t}$ is the volatility measure with ATS removed. The expressions of the regressions are as follows: $v_{i t}=\omega_{i t}+\delta_{i t} H_{i s t}+\lambda_{i t}, \quad \eta_{i t}=\omega_{i t}+\delta_{i t} H_{i s t}+\lambda_{i t} \quad \tau_{i t}=\omega_{i t}+\delta_{i t} H_{i s t}+\lambda_{i t}$.

The values in parentheses are the t-statistics. ${ }^{* * *}$ denotes significance at $1 \%,{ }^{* *}$ denotes significance at $5 \%$ and ${ }^{*}$ denotes significance at $10 \%$.

\begin{tabular}{|c|c|c|c|c|c|c|c|c|c|}
\hline & \multicolumn{3}{|c|}{$v$} & \multicolumn{3}{|c|}{$\eta$} & \multicolumn{3}{|c|}{$\tau$} \\
\hline & $\mathrm{Ha}$ & $H b$ & $H c$ & $H a$ & $H b$ & $H c$ & $H a$ & $H b$ & $H c$ \\
\hline \multicolumn{10}{|c|}{ Small Cap Index } \\
\hline \multirow[t]{2}{*}{$\left|\varepsilon_{\mathrm{AA}}\right|$} & -0.0002 & -0.0001 & -0.0004 & 0.0000 & 0.0000 & -0.0002 & $-0.0004^{* *}$ & $-0.0004^{* *}$ & $-0.0007^{*}$ \\
\hline & $(-0.99)$ & $(-0.67)$ & $(-0.96)$ & $(0.11)$ & $(0.25)$ & $(-0.43)$ & $(-2.53)$ & $(-2.11)$ & $(-1.70)$ \\
\hline \multirow[t]{2}{*}{$\left|\varepsilon_{\mathrm{AC}}\right|$} & $-0.0004^{* * *}$ & $-0.0003^{* *}$ & $-0.0006^{* *}$ & $-0.0003^{* *}$ & $-0.0002^{*}$ & $-0.0005^{* *}$ & $-0.0007^{* * *}$ & $-0.0006^{* * *}$ & $-0.0010^{* * *}$ \\
\hline & $(-3.02)$ & $(-2.45)$ & $(-2.54)$ & $(-2.25)$ & $(-1.84)$ & $(-2.13)$ & $(-5.63)$ & $(-4.87)$ & $(-4.00)$ \\
\hline \multirow[t]{2}{*}{$\left|\varepsilon_{\mathrm{CC}}\right|$} & $-0.0003^{* * *}$ & $-0.0002^{* *}$ & $-0.0005^{* * *}$ & $-0.0002^{* *}$ & -0.0002 & $-0.0004^{* *}$ & $-0.0006^{* * *}$ & $-0.0005^{* * *}$ & $-0.0009^{* * *}$ \\
\hline & $(-2.87)$ & $(-1.95)$ & $(-3.18)$ & $(-2.38)$ & $(-1.60)$ & $(-2.83)$ & $(-6.24)$ & $(-5.14)$ & $(-5.70)$ \\
\hline \multirow[t]{2}{*}{$\left|\varepsilon_{\mathrm{CA}}\right|$} & $-0.0004^{* * *}$ & $-0.0003^{* * *}$ & $-0.0006^{* *}$ & $-0.0003^{* *}$ & $-0.0002^{* *}$ & $-0.0005^{* *}$ & $-0.0007^{* * *}$ & $-0.0006^{* * *}$ & $-0.0010^{* * *}$ \\
\hline & $(-3.02)$ & $(-2.45)$ & $(-2.54)$ & $(-2.25)$ & $(-1.84)$ & $(-2.13)$ & $(-5.63)$ & $(-4.87)$ & $(-4.00)$ \\
\hline \multirow[t]{2}{*}{$\sigma_{R-A C}$} & $-0.0002^{* * *}$ & -0.0001 & $-0.0002^{* *}$ & $-0.0001^{* *}$ & 0.0000 & -0.0001 & $-0.0004^{* * *}$ & $-0.0002^{* * *}$ & $-0.0004^{* * *}$ \\
\hline & $(-2.87)$ & $(-0.98)$ & $(-1.62)$ & $(-1.65)$ & $(0.02)$ & $(-1.02)$ & $(-5.62)$ & $(-3.56)$ & $(-3.03)$ \\
\hline \multirow[t]{2}{*}{$\sigma_{R-A A}$} & $-0.0002^{* *}$ & -0.0001 & -0.0004 & -0.0001 & 0.0000 & -0.0003 & $-0.0005^{* * *}$ & $-0.0003^{* * *}$ & $-0.0007^{* *}$ \\
\hline & $(-1.82)$ & $(-0.92)$ & $(-1.31)$ & $(-1.07)$ & $(-0.32)$ & $(-0.99)$ & $(-3.64)$ & $(-2.59)$ & $(-2.11)$ \\
\hline \multirow[t]{2}{*}{$\sigma_{P}$} & $-0.0003^{* * *}$ & $-0.0001^{* *}$ & $-0.0003^{* *}$ & $-0.0002^{* *}$ & -0.0001 & $-0.0003^{* *}$ & $-0.0005^{* * *}$ & $-0.0004^{* * *}$ & $-0.0006^{* * *}$ \\
\hline & $(-3.75)$ & $(-2.01)$ & $(-2.57)$ & $(-2.75)$ & $(-1.19)$ & $(-1.99)$ & $(-7.27)$ & $(-5.46)$ & $(-4.71)$ \\
\hline \multirow[t]{2}{*}{$\sigma_{G K}$} & $-0.0002^{* * *}$ & 0.0000 & $-0.0002^{* *}$ & $-0.0001^{* *}$ & 0.0000 & -0.0001 & $-0.0004^{* * *}$ & $-0.0002^{* * * *}$ & $-0.0004^{* * * *}$ \\
\hline & $(-3.30)$ & $(-0.68)$ & $(-1.90)$ & $(-1.98)$ & $(0.47)$ & $(-0.97)$ & $(-7.09)$ & $(-4.59)$ & $(-4.72)$ \\
\hline \multirow[t]{2}{*}{ ST ATM Call } & $-0.0001^{* *}$ & 0.0000 & -0.0001 & 0.0000 & 0.0000 & 0.0000 & -0.0001 & 0.0000 & 0.0000 \\
\hline & $(-1.81)$ & $(-0.04)$ & $(-0.85)$ & $(-0.55)$ & $(1.17)$ & $(0.12)$ & $(-1.37)$ & $(0.28)$ & $(-0.51)$ \\
\hline \multirow[t]{2}{*}{$\begin{array}{c}S T A T M \\
\text { Call }^{*}\end{array}$} & $-0.0001^{* * *}$ & 0.0000 & -0.0001 & -0.0001 & 0.0000 & 0.0000 & $-0.0001^{* *}$ & 0.0000 & -0.0001 \\
\hline & $(-3.00)$ & $(-0.69)$ & $(-1.60)$ & $(-1.46)$ & $(0.81)$ & $(-0.38)$ & $(-2.42)$ & $(-0.27)$ & $(-1.16)$ \\
\hline
\end{tabular}


Table VIII. Panel B. Influence of herding in large cap stocks on the volatility measures of the Ibex-35 index. The data shown are the coefficients for the effect of the herding intensity measures on the volatility measures purged of volume effects and sorted by type of volume measure, where $v_{i t}$ is the volatility measure after removing the volume variable $V, \eta_{i t}$ is the volatility measure after removing the volume variable $N T$ and $\tau_{i t}$ is the volatility measure with ATS removed. The expressions of the regressions are as follows: $v_{i t}=\omega_{i t}+\delta_{i t} H_{i s t}+\lambda_{i t}, \quad \eta_{i t}=\omega_{i t}+\delta_{i t} H_{i s t}+\lambda_{i t} \quad \tau_{i t}=\omega_{i t}+\delta_{i t} H_{i s t}+\lambda_{i t}$.

The values in parentheses are the t-statistics. ${ }^{* * *}$ denotes significance at $1 \%,{ }^{* *}$ denotes significance at $5 \%$ and ${ }^{*}$ denotes significance at $10 \%$.

\begin{tabular}{|c|c|c|c|c|c|c|c|c|c|}
\hline & \multicolumn{3}{|c|}{$v$} & \multicolumn{3}{|c|}{$\eta$} & \multicolumn{3}{|c|}{$\tau$} \\
\hline & $\mathrm{Ha}$ & $H b$ & $H c$ & $H a$ & $H b$ & $H c$ & $\mathrm{Ha}$ & $H b$ & $H c$ \\
\hline \multicolumn{10}{|c|}{ Large Cap Index } \\
\hline$\left|\varepsilon_{\mathrm{AA}}\right|$ & $\begin{array}{c}-0.0002^{* * *} \\
(-2.84)\end{array}$ & $\begin{array}{c}-0.0002^{\text {*** }} \\
(-2.92)\end{array}$ & $\begin{array}{c}-0.0002^{* *} \\
(-2.67)\end{array}$ & $\begin{array}{r}-0.0001 \\
(-1.47)\end{array}$ & $\begin{array}{c}-0.0001^{* *} \\
(-1.62)\end{array}$ & $\begin{array}{c}-0.0002^{* *} \\
(-2.07)\end{array}$ & $\begin{array}{c}-0.0004^{* * *} \\
(-5.28)\end{array}$ & $\begin{array}{c}-0.0004^{* * *} \\
(-5.26)\end{array}$ & $\begin{array}{c}-0.0003^{\text {*** }} \\
(-3.72)\end{array}$ \\
\hline$\left|\varepsilon_{\mathrm{AC}}\right|$ & $\begin{array}{c}-0.0002^{* * *} \\
(-3.35)\end{array}$ & $\begin{array}{c}-0.0002^{\text {**** }} \\
(-3.62)\end{array}$ & $\begin{array}{c}-0.0002^{* * *} \\
(-3.64)\end{array}$ & $\begin{array}{c}-0.0001^{* *} \\
(-2.57)\end{array}$ & $\begin{array}{c}-0.0001^{* * * * *} \\
(-2.89)\end{array}$ & $\begin{array}{c}-0.0002^{* * *} \\
(-3.22)\end{array}$ & $\begin{array}{c}-0.0003^{* * *} \\
(-6.91)\end{array}$ & $\begin{array}{c}-0.0003^{* * *} \\
(-7.02)\end{array}$ & $\begin{array}{c}-0.0003^{\text {*** }} \\
(-5.20)\end{array}$ \\
\hline$\left|\varepsilon_{\mathrm{CC}}\right|$ & $\begin{array}{c}-0.0003^{* * *} \\
(-4.42)\end{array}$ & $\begin{array}{c}-0.0003^{* * *} \\
(-4.41)\end{array}$ & $\begin{array}{c}-0.0003^{* * *} \\
(-4.96)\end{array}$ & $\begin{array}{c}-0.0003^{* * *} \\
(-4.17)\end{array}$ & $\begin{array}{c}-0.0002^{* * *} \\
(-4.19)\end{array}$ & $\begin{array}{c}-0.0003^{* * *} \\
(-4.82)\end{array}$ & $\begin{array}{c}-0.0005^{* * *} \\
(-7.72)\end{array}$ & $\begin{array}{c}-0.0004^{* * *} \\
(-7.65)\end{array}$ & $\begin{array}{c}-0.0004^{* * *} \\
(-6.31)\end{array}$ \\
\hline$\left|\varepsilon_{\mathrm{CA}}\right|$ & $\begin{array}{c}-0.0002^{* * *} \\
(-3.35)\end{array}$ & $\begin{array}{c}-0.0002^{* * *} \\
(-3.62)\end{array}$ & $\begin{array}{c}-0.0002^{* * *} \\
(-3.64)\end{array}$ & $\begin{array}{c}-0.0001^{* *} \\
(-2.57)\end{array}$ & $\begin{array}{c}-0.0001^{* * *} \\
(-2.89)\end{array}$ & $\begin{array}{c}-0.0002^{* * *} \\
(-3.22)\end{array}$ & $\begin{array}{c}-0.0003^{* * *} \\
(-6.91)\end{array}$ & $\begin{array}{c}-0.0003^{* * *} \\
(-7.02)\end{array}$ & $\begin{array}{c}-0.0003^{* * *} \\
(-5.20)\end{array}$ \\
\hline$\sigma_{R-A C}$ & $\begin{array}{c}-0.0001^{* * *} \\
(-3.16)\end{array}$ & $\begin{array}{c}-0.0001^{* *} \\
(-2.34)\end{array}$ & $\begin{array}{c}0.0000 \\
(-1.48)\end{array}$ & $\begin{array}{c}0.0000^{* *} \\
(-1.82)\end{array}$ & $\begin{array}{c}0.0000 \\
(-1.06)\end{array}$ & $\begin{array}{c}0.0000 \\
(-0.76)\end{array}$ & $\begin{array}{c}-0.0002^{* * *} \\
(-6.98)\end{array}$ & $\begin{array}{c}-0.0002^{* * *} \\
(-6.01)\end{array}$ & $\begin{array}{c}-0.0001^{* * *} \\
(-3.20)\end{array}$ \\
\hline$\sigma_{R-A A}$ & $\begin{array}{c}-0.0001^{* * *} \\
(-3.31)\end{array}$ & $\begin{array}{c}-0.0001^{* *} \\
(-2.71)\end{array}$ & $\begin{array}{c}-0.0001^{* *} \\
(-2.72)\end{array}$ & $\begin{array}{c}-0.0001^{* *} \\
(-2.10)\end{array}$ & $\begin{array}{r}-0.0001 \\
(-1.55)\end{array}$ & $\begin{array}{c}-0.0001^{* *} \\
(-2.13)\end{array}$ & $\begin{array}{c}-0.0002^{\text {**** }} \\
(-7.21)\end{array}$ & $\begin{array}{c}-0.0002^{* * *} \\
(-6.46)\end{array}$ & $\begin{array}{c}-0.0002^{* * *} \\
(-4.41)\end{array}$ \\
\hline$\sigma_{P}$ & $\begin{array}{c}-0.0001^{* * *} \\
(-3.92)\end{array}$ & $\begin{array}{c}-0.0001^{* * * *} \\
(-3.54)\end{array}$ & $\begin{array}{c}-0.0001^{* * *} \\
(-3.45)\end{array}$ & $\begin{array}{c}-0.0001^{* * *} \\
(-3.04)\end{array}$ & $\begin{array}{c}-0.0001^{* *} \\
(-2.71)\end{array}$ & $\begin{array}{c}-0.0001^{* * *} \\
(-2.98)\end{array}$ & $\begin{array}{c}-0.0003^{* * *} \\
(-8.27)\end{array}$ & $\begin{array}{c}-0.0002^{* * *} \\
(-7.71)\end{array}$ & $\begin{array}{c}-0.0002^{\text {*** }} \\
(-5.30)\end{array}$ \\
\hline$\sigma_{G K}$ & $\begin{array}{c}-0.0001^{* * * *} \\
(-3.52)\end{array}$ & $\begin{array}{c}-0.0001^{* * *} \\
(-2.84)\end{array}$ & $\begin{array}{c}-0.0001^{* *} \\
(-2.10)\end{array}$ & $\begin{array}{c}-0.0001^{* *} \\
(-2.51)\end{array}$ & $\begin{array}{c}-0.0001^{* *} \\
(-1.87)\end{array}$ & $\begin{array}{r}-0.0001 \\
(-1.53)\end{array}$ & $\begin{array}{c}-0.0002^{* * * *} \\
(-7.45)\end{array}$ & $\begin{array}{c}-0.0002^{* * *} \\
(-6.62)\end{array}$ & $\begin{array}{c}-0.0001^{* * *} \\
(-3.91)\end{array}$ \\
\hline ST ATM Call & $\begin{array}{r}0.0000 \\
(-1.12)\end{array}$ & $\begin{array}{c}0.0000 \\
(-0.37)\end{array}$ & $\begin{array}{c}0.0000 \\
(0.29)\end{array}$ & $\begin{array}{c}0.0000 \\
(-0.01)\end{array}$ & $\begin{array}{c}0.0000 \\
(0.66)\end{array}$ & $\begin{array}{c}0.0000 \\
(0.78)\end{array}$ & $\begin{array}{c}0.0000 \\
(-0.97)\end{array}$ & $\begin{array}{c}0.0000 \\
(-0.25)\end{array}$ & $\begin{array}{c}0.0000 \\
(0.31)\end{array}$ \\
\hline $\begin{array}{c}S T \text { ATM } \\
\text { Call }^{*}\end{array}$ & $\begin{array}{c}-0.0001^{* *} \\
(-2.70)\end{array}$ & $\begin{array}{c}0.0000^{* *} \\
(-1.92)\end{array}$ & $\begin{array}{l}0.0000 \\
(-0.94)\end{array}$ & $\begin{array}{l}0.0000 \\
(-1.29)\end{array}$ & $\begin{array}{c}0.0000 \\
(-0.58)\end{array}$ & $\begin{array}{c}0.0000 \\
(-0.28)\end{array}$ & $\begin{array}{c}-0.0001^{* *} \\
(-2.46)\end{array}$ & $\begin{array}{c}0.0000^{* *} \\
(-1.72)\end{array}$ & $\begin{array}{l}0.0000 \\
(-0.90)\end{array}$ \\
\hline
\end{tabular}


Tabla IXa. Results of dynamic volatility forecast using models without herding intensity variables (a) and with herding intensity variables (b). The table shows the prediction error estimates for each of the proposed models. $\sqrt{ }$ : Square root of error, MAE: Mean Absolute Error. MAPE: Mean Absolute Percentage ${ }^{* *}$ denote minimum error values.

$$
\begin{array}{ll}
\text { Model 1a: } & \sigma_{i t}=\alpha_{i}+\alpha_{i m} M_{t}+\sum_{j=1}^{12} \rho_{i j} \sigma_{i t-j}+\phi_{i} V_{i t}+e_{i t} \\
\text { Model 1b: } & \sigma_{i t}=\alpha_{i}+\alpha_{i m} M_{t}+\sum_{j=1}^{12} \rho_{i j} \sigma_{i t-j}+\phi_{i} V_{i t}+\sum_{s=1}^{3} \varpi_{s} H_{s}+e_{i t} \\
\text { Model 2a: } & \sigma_{i t}=\alpha_{i}+\alpha_{i m} M_{t}+\sum_{j=1}^{12} \rho_{i j} \sigma_{i t-j}+\theta_{i} N T_{i t}+e_{i t} \\
\text { Model 2b: } & \sigma_{i t}=\alpha_{i}+\alpha_{i m} M_{t}+\sum_{j=1}^{12} \rho_{i j} \sigma_{i t-j}+\theta_{i} N T_{i t}+\sum_{s=1}^{3} \varpi_{s} H_{s}+e_{i t} \\
\text { Model 3a: } & \sigma_{i t}=\alpha_{i}+\alpha_{i m} M_{t}+\sum_{j=1}^{12} \rho_{i j} \sigma_{i t-j}+\gamma_{i} A T S_{i t}+e_{i t} \\
\text { Model 3b: } & \sigma_{i t}=\alpha_{i}+\alpha_{i m} M_{t}+\sum_{j=1}^{12} \rho_{i j} \sigma_{i t-j}+\gamma_{i} A T S_{i t}+\sum_{s=1}^{3} w_{s} H_{s}+e_{i t}
\end{array}
$$

\begin{tabular}{|c|c|c|c|c|c|c|c|}
\hline & & Mod.1a & Mod.1b & Mod.2a & Mod.2b & Mod.3a & Mod.3b \\
\hline \multirow{3}{*}{$\left|\varepsilon_{\mathrm{AA}}\right|$} & $\sqrt{ }$ & $0.00927^{*}$ & 0.01039 & $0.00896^{*}$ & 0.00944 & $0.00795^{*}$ & 0.01003 \\
\hline & MAE & $0.00826^{*}$ & 0.00939 & $0.00797^{*}$ & 0.00847 & $0.00693^{*}$ & 0.00902 \\
\hline & MAPE & $72.76^{*}$ & 82.63 & $73.21^{*}$ & 77.30 & $66.31^{*}$ & 82.73 \\
\hline \multirow[t]{3}{*}{$\left|\varepsilon_{\mathrm{AC}}\right|$} & $\sqrt{ }$ & 0.00771 & $0.00698^{*}$ & 0.00729 & $0.00610^{*}$ & 0.01003 & $0.00735^{*}$ \\
\hline & MAE & 0.00688 & $0.00618^{*}$ & 0.00644 & $0.00529^{*}$ & 0.00902 & $0.00651^{*}$ \\
\hline & MAPE & 60.47 & $53.51^{*}$ & 57.47 & $46.54^{*}$ & 82.73 & $57.97^{*}$ \\
\hline \multirow[t]{3}{*}{$\left|\varepsilon_{\mathrm{CC}}\right|$} & $\sqrt{ }$ & 0.00907 & $0.00758^{*}$ & 0.00835 & $0.00643^{*}$ & $0.00795^{*}$ & 0.00831 \\
\hline & MAE & 0.00804 & $0.00664^{*}$ & 0.00737 & $0.00556^{*}$ & $0.00697^{*}$ & 0.00731 \\
\hline & MAPE & 92.76 & $79.39^{*}$ & 85.64 & $67.04^{*}$ & $81.25^{*}$ & 84.85 \\
\hline \multirow[t]{3}{*}{$\left|\varepsilon_{\mathrm{CA}}\right|$} & $\sqrt{ }$ & 0.00397 & $0.00370^{*}$ & 0.003843 & $0.00328^{*}$ & $0.00345^{*}$ & 0.00366 \\
\hline & MAE & 0.00356 & $0.00328^{*}$ & 0.00344 & $0.00288^{*}$ & $0.00301^{*}$ & 0.00327 \\
\hline & MAPE & 103.71 & $98.57^{*}$ & 94.94 & $82.57^{*}$ & $88.63^{*}$ & 93.84 \\
\hline \multirow[t]{3}{*}{$\sigma_{R-A C}$} & $\sqrt{ }$ & 0.00722 & $0.00680^{*}$ & 0.00655 & $0.00535^{*}$ & $0.00521^{*}$ & 0.00679 \\
\hline & MAE & 0.00686 & $0.00648^{*}$ & 0.00627 & $0.00509^{*}$ & $0.00484^{*}$ & 0.00655 \\
\hline & MAPE & 113.77 & $107.10^{*}$ & 103.64 & $84.48^{*}$ & $82.21^{*}$ & 107.85 \\
\hline \multirow[t]{3}{*}{$\sigma_{R-A A}$} & $\sqrt{ }$ & 0.00876 & $0.00763^{*}$ & 0.00797 & $0.00573^{*}$ & $0.00650^{*}$ & 0.00773 \\
\hline & MAE & 0.00834 & $0.00720^{*}$ & 0.00764 & $0.00537^{*}$ & $0.00609^{*}$ & 0.00741 \\
\hline & MAPE & 120.99 & $104.66^{*}$ & 110.38 & $78.72^{*}$ & $90.28^{*}$ & 107.40 \\
\hline \multirow[t]{3}{*}{$\sigma_{P}$} & $\sqrt{ }$ & 0.00869 & $0.00808^{*}$ & 0.00820 & $0.00730^{*}$ & $0.00787^{*}$ & 0.00847 \\
\hline & MAE & 0.00725 & $0.00629^{*}$ & 0.00657 & $0.00495^{*}$ & $0.00575^{*}$ & 0.00670 \\
\hline & MAPE & 115.38 & $98.23^{*}$ & 103.58 & $74.86^{*}$ & $90.57^{*}$ & 106.15 \\
\hline \multirow[t]{3}{*}{$\sigma_{G K}$} & $\sqrt{ }$ & 0.00698 & $0.00652^{*}$ & 0.00625 & $0.00501^{*}$ & $0.00518^{*}$ & 0.00660 \\
\hline & MAE & 0.00654 & $0.00606^{*}$ & 00.587 & $0.00459^{*}$ & $0.00475^{*}$ & 0.00624 \\
\hline & MAPE & 114.57 & $106.54^{*}$ & 103.03 & $81.69^{*}$ & $85.50^{*}$ & 109.37 \\
\hline \multirow[t]{3}{*}{ ST ATM Call } & $\sqrt{ }$ & 0.00758 & $0.00563^{*}$ & 0.00712 & $0.00459^{*}$ & 0.00652 & $0.00616^{*}$ \\
\hline & MAE & 0.00695 & $0.00494^{*}$ & 0.00655 & $0.00404^{*}$ & 0.00593 & $0.00559^{*}$ \\
\hline & MAPE & 92.22 & $66.53^{*}$ & 88.10 & $56.10^{*}$ & 81.97 & $78.56^{*}$ \\
\hline
\end{tabular}

where $\sigma_{\text {it }}$ is the value on day $t$ of each of the volatility measures considered, where $i$ can take ten different values, $M_{t}$ is a dummy variable that takes a value of 1 for Mondays and 0 the remaining days of the week, $V$ is volume traded in Euros, $N T$ is volume traded in number of trades and ATS is average trade size and $\mathrm{H}_{\mathrm{s}}$ is the variable related to herding. 
Tabla IXb. Results of static volatility forecast using models without herding intensity variables (a) and with herding intensity variables (b).. The table shows the prediction error estimates for each of the proposed models. $\sqrt{ }$ : Square root of error, MAE: Mean Absolute Error. MAPE: Mean Absolute Percentage $^{* *}$ denote minimum error values.

$$
\begin{array}{ll}
\text { Model 1a: } & \sigma_{i t}=\alpha_{i}+\alpha_{i m} M_{t}+\sum_{j=1}^{12} \rho_{i j} \sigma_{i t-j}+\phi_{i} V_{i t}+e_{i t} \\
\text { Model 1b: } & \sigma_{i t}=\alpha_{i}+\alpha_{i m} M_{t}+\sum_{j=1}^{12} \rho_{i j} \sigma_{i t-j}+\phi_{i} V_{i t}+\sum_{s=1}^{3} \varpi_{s} H_{s}+e_{i t} \\
\text { Model 2a: } & \sigma_{i t}=\alpha_{i}+\alpha_{i m} M_{t}+\sum_{j=1}^{12} \rho_{i j} \sigma_{i t-j}+\theta_{i} N T_{i t}+e_{i t} \\
\text { Model 2b: } & \sigma_{i t}=\alpha_{i}+\alpha_{i m} M_{t}+\sum_{j=1}^{12} \rho_{i j} \sigma_{i t-j}+\theta_{i} N T_{i t}+\sum_{s=1}^{3} \varpi_{s} H_{s}+e_{i t} \\
\text { Model 3a: } & \sigma_{i t}=\alpha_{i}+\alpha_{i m} M_{t}+\sum_{j=1}^{12} \rho_{i j} \sigma_{i t-j}+\gamma_{i} A T S_{i t}+e_{i t} \\
\text { Model 3b: } & \sigma_{i t}=\alpha_{i}+\alpha_{i m} M_{t}+\sum_{j=1}^{12} \rho_{i j} \sigma_{i t-j}+\gamma_{i} A T S_{i t}+\sum_{s=1}^{3} w_{s} H_{s}+e_{i t}
\end{array}
$$

\begin{tabular}{|c|c|c|c|c|c|c|c|}
\hline & & Mod.1a & Mod.1b & Mod.2a & Mod.2b & Mod.3a & Mod.3b \\
\hline \multirow[t]{3}{*}{$\left|\varepsilon_{\mathrm{AA}}\right|$} & $\sqrt{ }$ & $0.00628^{*}$ & 0.00675 & $0.00628^{*}$ & 0.00647 & $0.00600^{*}$ & 0.00675 \\
\hline & MAE & $0.00537^{*}$ & 0.00577 & $0.00536^{*}$ & 0.00551 & $0.00513^{*}$ & 0.00577 \\
\hline & MAPE & $48.49^{*}$ & 54.17 & $50.06^{*}$ & 52.37 & $47.27^{*}$ & 55.68 \\
\hline \multirow[t]{3}{*}{$\left|\varepsilon_{\mathrm{AC}}\right|$} & $\sqrt{ }$ & 0.00556 & $0.00516^{*}$ & 0.00559 & $0.00498^{*}$ & $0.00526^{*}$ & 0.00548 \\
\hline & MAE & 0.00470 & $0.00430^{*}$ & 0.00473 & $0.00412^{*}$ & $0.00442^{*}$ & 0.00463 \\
\hline & MAPE & 43.91 & $38.60^{*}$ & 43.77 & $35.70^{*}$ & $39.58^{*}$ & 41.52 \\
\hline \multirow[t]{3}{*}{$\left|\varepsilon_{\mathrm{CC}}\right|$} & $\sqrt{ }$ & 0.00593 & $0.00536^{*}$ & 0.00584 & $0.00515^{*}$ & $0.00561^{*}$ & 0.00574 \\
\hline & MAE & 0.00516 & $0.00460^{*}$ & 0.00510 & $0.00438^{*}$ & $0.00489^{*}$ & 0.00501 \\
\hline & MAPE & 59.54 & $51.65^{*}$ & 58.17 & $48.01^{*}$ & $52.38^{*}$ & 54.33 \\
\hline \multirow[t]{3}{*}{$\left|\varepsilon_{\mathrm{CA}}\right|$} & $\sqrt{ }$ & 0.00287 & $0.00279^{*}$ & $0.00283^{*}$ & 0.00328 & $0.00274^{*}$ & 0.00279 \\
\hline & MAE & 0.00242 & $0.00234^{*}$ & $0.00239^{*}$ & 0.00288 & $0.00225^{*}$ & 0.00234 \\
\hline & MAPE & 77.04 & $77.77^{*}$ & $70.11^{*}$ & 82.57 & $67.22^{*}$ & 70.06 \\
\hline \multirow[t]{3}{*}{$\sigma_{R-A C}$} & $\sqrt{ }$ & 0.00223 & $0.00216^{*}$ & 0.00232 & $0.00201^{*}$ & $0.00185^{*}$ & 0.00223 \\
\hline & MAE & 0.00197 & $0.00191^{*}$ & 0.00203 & $0.00172^{*}$ & $0.00153^{*}$ & 0.00194 \\
\hline & MAPE & 32.76 & $31.50^{*}$ & 33.81 & $28.27^{*}$ & $24.69^{*}$ & 31.90 \\
\hline \multirow[t]{3}{*}{$\sigma_{R-A A}$} & $\sqrt{ }$ & 0.00280 & $0.00250^{*}$ & 0.00281 & $0.00223^{*}$ & $0.00235^{*}$ & 0.00264 \\
\hline & MAE & 0.00248 & $0.00216^{*}$ & 0.00248 & $0.00185^{*}$ & $0.00196^{*}$ & 0.00226 \\
\hline & MAPE & 36.47 & $31.73^{*}$ & 36.43 & $27.10^{*}$ & $28.65^{*}$ & 33.23 \\
\hline \multirow[t]{3}{*}{$\sigma_{P}$} & $\sqrt{ }$ & 0.00571 & $0.00568^{*}$ & 0.00573 & $0.00562^{*}$ & $0.00564^{*}$ & 0.00583 \\
\hline & MAE & 0.00336 & $0.00311^{*}$ & 0.00334 & $0.00291^{*}$ & $0.00309^{*}$ & 0.00330 \\
\hline & MAPE & 47.79 & $42.08^{*}$ & 47.47 & $37.91^{*}$ & $40.82^{*}$ & 45.24 \\
\hline \multirow[t]{3}{*}{$\sigma_{G K}$} & $\sqrt{ }$ & 0.00279 & $0.00267^{*}$ & 0.00283 & $0.00249^{*}$ & $0.00238^{*}$ & 0.00274 \\
\hline & MAE & 0.00235 & $0.00225^{*}$ & 0.00240 & $0.00209^{*}$ & $0.00197^{*}$ & 0.00229 \\
\hline & MAPE & 42.33 & $39.97^{*}$ & 42.91 & $36.44^{*}$ & $34.09^{*}$ & 40.66 \\
\hline \multirow[t]{3}{*}{ ST ATM Call } & $\sqrt{ }$ & 0.00187 & $0.00179^{*}$ & 0.00187 & $0.00176^{*}$ & 0.00181 & $0.00179^{*}$ \\
\hline & MAE & 0.00140 & $0.00118^{*}$ & 0.00140 & $0.00113^{*}$ & 0.00128 & $0.00123^{*}$ \\
\hline & MAPE & 13.99 & $11.55^{*}$ & 14.92 & $12.11^{*}$ & 14.59 & $14.87^{*}$ \\
\hline
\end{tabular}

where $\sigma_{\mathrm{it}}$ is the value on day $t$ of each of the volatility measures considered, where $i$ can take ten different values, $M_{t}$ is a dummy variable that takes a value of 1 for Mondays and 0 the remaining days of the week, $V$ is volume traded in Euros, $N T$ is volume traded in number of trades and ATS is average trade size and $\mathrm{H}_{\mathrm{s}}$ is the variable related to herding. 